\title{
VII.
}

\section{Ueber einige seltenere Erscheinungen nach apoplectischen Anfällen im Anschluss an einen complicirteren neuropathologischen Fall').}

\author{
Von Dr. S. H. Scheiber in Budapest.
}

I.

Die Grundlage zu dieser Arbeit bildet ein höchst complicirter neuropathologischer Fall, bei welchem sämmtliche Abschnitte des Centralnervensystems, das Gehirn, das verlängerte und das Rückenmark, in gewissen Zeiträumen nach einander in absteigender Reihe erkrankten. Dieser Fall bietet, abgesehen von seinem diagnostischen Interesse, mehrere Erscheinungen dar, die theils wegen ihrer Eigenthümlichkeit, theils wegen ihrer Seltenheit für den Nervenpathologen von einigem Interesse sein dürften, weshalb dieselben in dem II. Abschnitte näher besprochen und mit anderen Fällen verglichen werden sollen. Ohne auf Einzelheiten hier näher einzugehen, will jch nur vorläufig bemerken, dass die Fälle sich hauptsächlich auf zur Symptomatologie der Hirnblutungen und deren Folgezuständen gehörige Erscheinungen beziehen. Ich gehe sogleich zur Schilderung jenes complicirten Krankheitsfalles, den ich der Freundlichkeit meines verehrten Freundes und Collegen Dr. H. Pollak verdanke, über:

1. Krankengesehich $\mathbf{t}$.

Anamnesis. Sch. K., 36 Jahre alt, Buchhalter, ledig, in Budapest geboren und daselbst wohnhaft, neuropathisch belastet, bat angeblich nie an Syphilis gelitten, war bis zu seinem 25. Lebensjahre angeblich stets gesund.

1) Vorgetragen im Budapester ärztlichen Vereine in der Sitzung vom 25. April 1885. Die Jahreszahlen des Alters und der Krankheitsperioden sind überall mit Bezug auf das Datum des Vortrages angegeben. 
Von dieser Zeit an, nehmlich seit 11 Jahren, leidet Patient an öfteren starken Anfällen von Schwindel und Kopfschmerzen, und wurde seit dieser Zeit zu wiederholten Malen, und zwar bald auf gewisse Veranlassungen, bald obne solche, von sogenannten Obnmachtsanfällen befallen. Sein gegenwärtiges schwereres Leiden datirt seit 5 Jahren, nehmlich seit dem Jahre 1880, wo er 31 Jahre alt war.

Obwohl seine Eltern ebenfalls in Budapest leben, so wohnte Patient für sich allein in einem gemietheten Monatzimmer. Als er am 13. Februar 1880 Abends aus dem Gasthause, wo er zu Abend gegessen hatte, nach Hause ging, hatte er sich noch ganz wohl gefühlt. In's Zimmer tretend fing er plötzlich an zu niesen, und im Momente des Niesens fühlte er einen heftigen Schmerz und Ameisenkriechen in der rechten Hand, gerade so als bätte er den Ellenbogen stark angeschlagen, nur dass er dieses Gefühl nicht allein im kleinen Finger, wie dies in solcben Fällen gewöhnlich geschieht, sondern in der ganzen Hand hatte. Nachdem die Schmerzen auf kalte Umschläge und Nassiren nicht nachliessen, legte er sich zu Bette, wo er trotz der Schmerzen endlich einschlief und die ganze Nacht durchschlief.

Frühmorgens waren indess die Schmerzen und das Ameisenkriechen nicht nur nicht gewichen, sondern noch stärker, dagegen verspürte er weiter kein anderes Leiden. Während des Ankleidens jedoch bekam Pat. plötzlich Schwindel, verjor das Bewusstsein und stürzte zu Boden. Als er zu sich kain, sah er sich neben einem Sessel am Boden liegend; wie lange er in diesem Zustande dalag, kann er genau nicht wissen, da sonst niemand im Zimmer war. Nur aus dem Umstande, dass die Zeit noch nicht sehr vorgerückt war, glaubt er schliessen zu tönnen, dass die Bewusstlosigkeit nicht länger als etwa $\frac{1}{2}$ Stunde gedauert baben dürfte. $Z u$ sich gekommen füblte er nun nocb heftigere Schmerzen und zwar jetzt schon im ganzen rechten Arm und in der rechten Kopf-, Halsund Brusthä]fte; das Ameisenkriechen blieb blos auf die Hand beschränkt. Ausserdem war der Kopf etwas eingenommen, und er fühlte eine bochgradige Schwäche im recbten Arm und Bein. Dabei konnte er indess immerbin gehen und sich weiter ankleiden.

Nach dem Ankleiden ging er sogar allein zu Fuss in die Wohnung seiner Mutter, wo er sich angekleidet auf's Canapé niederlegte. Des Nachmittags schien er sich besser zu fühlen, ging in die Kanzlei, und schrieb auch daseibst ein Telegramm, obwohl seine Hand schwach und unsicher war. Indessen konnte er länger als $\frac{1}{2}$ Stunde auch hier nicht verweilen, da er eine grosse Schwäche und ein allgemeines Unwohlsein fühlte. $\mathrm{Er}$ ging demnach wieder zur Mutter, bei der er von nun ab stets wohnte, und legte sich zu Bette.

Noch am selben Abend bekam Pat. starkes Schluchzen, welches 6 Tage Tag und Nacht anbielt und in dicht auf einander folgenden Anfällen kam. Während dieser Zeit kam Pat. stark herab, musste wegen grosser Schwäche 2 Wochen im Bette zubringen und noch 6 Wochen das Zimmer häten; die rechte untere Extremität ward noch schwächer als zuror, 
so dass während des Gehens das Knie oft zusammenschnappte und der Kranke in der rechten Wade eine Spannung fühlte; anch im rechten Arm hielt die grosse Schwäche an, so dass er die Feder nur schwer und unsicher fübren konnte. Nach der obgenannten Zeit indess waren seine Ernährung und seine Kräfte soweit wieder hergestellt, dass er seiner Beschäftigung nachgehen konnte. Er konnte aber auch jetzt nur noch kurze Spaziergänge wachen und musste sich öfter unterwegs ausruhen, da die rechte untere Extremität sehr schnell ermüdete. Die Schmerzen, die sich zwar am Kopfe, Halse und auf der Brust milderten, blieben indessen noch in der ganzen rechten oberen Extremität, sowie das Ameisenkriechen in der rechten Hand ungeschwächt, und sind noch heut zu Tage nicht verschwunden.

Gerade ein Jahr später, im Februar 1881, bekam Pat. Schlingbeschwerden, wurde heiser und fing andurch die Nase zu sprechen. Diese Erscheinungen stellten sich indess nicht plötzlich, in apoplectiformer Weise, sondern sehr langsam ein, nehmlich in der. Weise, dass Pat. einmal bei Tisch bemerkte, dass beim Essen der Suppe seine linke Nase feucht wird, so dass er anfangs glaubte, dass er einen Schnupfen bekomme. Am nächsten Tage kam beim Essen warmer Flüssigkeiten (Suppe, Kaffee) schon mehr Flüssigkeit durch die Nase; am 3. Tag konnte er überhaupt warme Flüssigkeiten nicht mehr herunterbringen, da alles durch die Nase herauskam; er vermochte nur noch kalte Flüssigkeiten und feste Speișen zu schlucken. Endlich gingen auch diese schwer herunter, bis er endlich kaum mehr etwas in den Magen bringen konnte. Während dieser Zeit wurde anch die Heiserkeit so hochgradig, dass man ihn kaum verstehen konnte, zumal da die Sprache zugleich stark näselnd wurde. Dieser ganze Zustand hatte sich innerhalb 6 Tagen entwickelt, während welcher Zeit indess sein Allgemeinbefinden nicht im Mindesten gestört war, so dass er noch in den ersten 2 Tagen des Leidens seine Kanzleigeschäfte versah.

In Folge elektrischer Behandlung besserten sich allmäblich zwar diese Symptome, aber ganz sind sie nicht geschwunden, bestehen vielmehr in gewissem Grade noch heute fort. Hervorzuheben ist, dass die Flüssigkeiten stets blos in die linke Nasenhöble traten und nie in die rechte, und dass Pat. die im Rachen stecken gebliebenen Bissen stets nur in der linken Rachenhälfte fühlte, nie in der rechten. Er behauptet ferner ganz bestimmt, dass er bei dem ersten Schlingacte nie Schwierigkeiten fühlte; die Speisen blieben immer erst im Schlunde stecken, so dass also eine Functionsstörung nicht zu bemerken war, insoweit der Schlingact von der Thätigkeit der Zunge abbängt. Selbstverständlich war Pat. in Folge der unvollständigen Ernährung sebr herabgekommen; sobald er indess besser schlingen und mehr Nahrung zu sich nehmen konnte, erholte er sich wieder und konnte alsbald seiner Beschäftigung nachgehen.

Im Sommer des Jahres 1882 bemerkte Pat, als er eine Kaltwassercur durchmachte, dass die ersten 3 Spatia interossea der linken Hand 
auffallend abmagerten; später wurde die Beweglichkeit des Zeige- und Mittelfingers immer beschränkter, und endlich hatie sich auch ibre Form verändert, sowie auch später eine Abmagerung des Thenar und Antithenar sich einstellte. Im darauffolgenden Winter fing der Kranke an zu husten, und hustet seitdem immer mehr oder weniger heftig, besonders des Nachts, mit mehr oder weniger copiösem gelblichem Schleim.

Durch alle diese krankhaften Zufälle litt die Constitution des Kranken mehr und mehr; während sein Körpergewicht vor dem Jahre $188062 \mathrm{~kg}$ betrug, kam er allmählich auf 52 , endlich sogar auf 49 herunter, erholte sich aber in den letzteren Jahren wieder auf 52. Es versteht sich von selbst, dass der Kranke alles that, was er nur zur Restaurirung seiner Gesundbeit thun konnte. Jeden Sommer besuchte er die ibm empfohlenen Badeorte, benutzte zu Hause Elektricität, Massage, Gymnastik, und liess sich jedwede anderweitige symptomatische Behandlung angedeihen. Innerlich nahm er zu verschiedenen Zeiten Bromkali, Jodkali, Quecksilberpräparate u. s. w.

Ich sah Pat. zu allererst im November 1883 und hatte seitdem Gelegenheit, ihn fast ununterbrochen zu beobachiten. Als er zum erstenmal zu mir kam, konnte ich folgenden

\section{Status praesens}

constatiren. Der Kranke ist von kleiner Statur, mittlerer Constitution, mittelmässig genährt, Hautfarbe blassgelb, Schädel normal gebaut, auf Percussion nirgends empfindlich. Der Kranke hat auf der rechten Seite eine leichte motorische und eine schwere sensible Lähmung. Muskelparese ist an der rechten unteren Extremität gar nicht, an der rechten Gesichts- und Halshälfte nur in geringem Grade vorhanden. So ist z. B. wegen leichter Paresis des rechten $\mathbf{M}$. sternocleidomastoideus der Kopf etwas gegen die linke Schulter, das Kinn etwas nach rechts und oben gerichtet. An der Facialparese nehmen auch die oberen $\mathrm{Zweige}$ Theil, wenigstens wird die Stirn rechts weniger in Runzeln gebracht als links. Am stärksten ist indess die Parese an der rechten oberen Extremität und an der rechten Stammmusculatur ausgedrückt, nehmlich dort, wo, wie wir sehen werden, auch zugleich die sensible Sphäre am meisten afficirt ist. Pat. führt mit dem rechten Arm alle möglichen Bewegungen aus, jedoch mit viel geringerer Kraft und geringeren Elongationen, wie mit der linken oberen Extremität. An dem Dynamometer drückt Pat. mit der rechten Hand 5, mit der linken $10 \mathrm{~kg}$. Die rechte Schulter und Brustwarze, sowie das untere Ende der rechten Scapula stehen um $1 \mathrm{~cm}$ niederer als linkerseits. Der innere Rand der rechten Scapula steht weit ab vom Brustkorbe, was links nicht der Fall ist. Bei tiefer Inspiration bleibt die rechte Brusthälfte hinter der linken etwas zurück.

Die Uvula ist verdickt, länger als gewöhnlich, und hängt senkrecht herab; die Spitze ruht auf der Zunge auf, und ist vollständig unbeweglich sowohl auf mechanische, als auf elektrische Reize, sowie auch bei der Phonation. Der weiche Gaumen ist rechts blässer als links, zeigt rechterseits sẹp 
wenig Beweglichkeit, ist nicht blos wie die Uvula unempfindlich und obne jede reflectorische Reizbarkeit, sondern auch verdünnt und atrophisch, besonders entsprechend dem Arcus palatoglossus und palatopharyngeus, die blos dünne Schleimhautfalten bilden ohne jeden Tonus and leicht dehnbar sind. Links dagegen sind die beiden Arcus röther, dicker, bilden feste gespannte und auf den mindesten Reiz lebhaft reagirende Falten. Ebenso ist der Schlund rechterseits gelähmt und gegen jedweden Reiz unempfindlich, während er links normal ist. Die laryngoskopische Untersuchung zeigt vollständige Unbeweglichkeit des rechten Stimmbandes (s. weiter unten noch Näheres darüber bei der Diagnose).

Auf der ganzen rechten Körperhälfte ist die Tast-, Temperatur- und Schmerzempfindung stark herabgesetzt. Die Hemianästhesie geht im Gesicht, am Halse und am Stamm, sowie in der Mundhöhle und im Rachen bis zur Mittellinie. An der rechten unteren Extremität reicht sie indess blos bis zu den Knöcheln; am rechten Fusse ist die Empfindung voliständig normal. Von den Knöcheln nach aufwärts beginnt die Anästhesie nicht plötzlich bochgradig zu werden, sondern sie wird allmählich stärker, je weiter hinauf man untersucht. So ist der Unterschied zwischen rechts und links nicht so gross bis zum Knie, wie oberhalb des Knies. In allen anästhetischen Gebieten ist auch die 'elektrocutane Reaction gegen beide Stromesarten theils vermindert, theils ganz geschwunden. Um einzelne Beispiele anfzuführen, ist in Bezug des Tastgefühles zu bemerken, dass Pat. am rechten Vorder- und Oberarm beide Zirkelspitzen nicht einmal noch bei $16 \mathrm{~cm}$ getrennt fühlt, während doch dieselben unter normalen VerhäItnissen durchschnittlich am Vorderarm bei 4 , am Oberarm bei $7 \mathrm{~cm}$ getrennt gefühlt werden. In Betreff der Verminderung der elektrocutanen Empfindlicbkeit ist zu bemerken, dass bei der äusseren elektrischen Behandlung des Keblkopfes der Kranke den Strom rechts gar nicht fühlt, wenn derselbe auch so stark ist, dass er linkerseits nicht mehr ertragen wird. (Ueber die elektromusculäre Reaction später.)

Die Anästhesie erstreckt sich in geringerem Grade auf die Muskelempfindung, den sog. Muskelsinn, sowie auch (mit A usnahme des Gehörs) auf die Sinnesorgane. In Bezug des Muskelsinns ist zu bemerken, dass Pat. mit der rechten Hand Gewichte nicht so gut abschätzen kann, wie mit der linken, und dass er mit geschlossenen Augen stehend stark schwankt, aber nicht umfällt (statische Ataxie). Was speciell das Sehen betrifft, so ist die rechte Pupille constant etwas weiter als die linke, der Lichtreflex normal. Mit dem rechten Auge allein sieht Pat. die Buchstaben des gewöhnlichen Druckes undeutlich, wie verschwommen, mit beiden Augen gut. Die genauere Untersuchung wurde von meinem Freunde, Primaraugenarzt Dr. Vidor ausgeführt. Dieselbe ergab, dass Pat. mit dem rechten Auge Jäger No.1 nur mit Hülfe einer Linse gut sieht. Der Farbensinn normal; mit dem Spiegel war ausser einer stärkeren Füllung der Venen nichts Abnormes zu sehen; dann ist geringer Grad von Nystagmus rotatorius vorhanden, was aber wabrscheinlich angeboren ist. Der Ge- 
sichtskreis geht rechterseits nicht so weit nach aussen als links, indem der Kranke angiebt, dass wenn er rechts zurücksieht, er die Gegenstände nicht so deutlich sieht und nicht so weit sehen kann, als wenn er links zurücksieht. Dies spricht für einen geringen Grad von Hemianopsie, die wahrscheinlich im Beginne der Krankheit viel intensiver gewesen ist, aber der Kranke mag dies damals nicht beachtet haben.

Reizungserscheinungen in der motorischen Sphäre (es ist hier immer nur von der hemiplegischen Seite die Rede), namentlich Contracturen, existiren nicht, wenn man nicht die Wadenspannung rechterseits hieher rechnen will, die sich auch jetzt noch hie und da während des Gebens einstellt. Um so stärker sind die Reizungserscheinungen in der sensiblen Sphäre, und zwar in Form der schon Eingangs erwähnten Schmerzen in der rechten oberen Extremität und von Ameisenkriechen in der rechten Hand. Diese Symptome bestehen auch jetzt noch continuirlich, nur sind die Schmerzen bald stärker, bald schwäcber. In Bezug der Grade derselben unterscbeidet der Kranke schon ans Gewohnheit dreierlei: schwache, mittlere nnd starke. Zumeist sind sie schwach, und dann sind sie blos auf den Arm beschränkt, und zwar auf die äussere und hintere Seite des Ober-, auf die Radialseite des Vorderarms, auf den Daumen und Zeigefinger, also entsprechend dem N. musculocutaneus, dem Ramus cutaneus externus des N. radialis, sowie den Fingerendigungen dieses Nerven. Sind die Schmerzen stark, dann breiten sich dieselben auch auf die rechte Thorax-, Hals- und Kopfhälfte aus.

Die Intensität der Schmerzen ist zwar weder an Jahreszeiten noch an Witterungswechsel gebunden, indess kommen doch starke Schmerzen im Winter ofter vor, als im Sommer. Wenn Pat. viel spricht und vorliest, besonders aber bei Gemüthsaufregungen, bekommt er immer starke Schmerzen. Das Ameisenkriechen wird immer blos in den Fingern gefühlt.

Vas omotorische Erscheinungen sind nicht wahrzunehmen. Von trophischen Erscheinungen ist zu erwähnen, dass auf der hemiplegischen Seite am Brustkorb öfter Herpes zoster vorkam; auch dürfte die Hypertrophie der Uvula hiehergehören.

An der linken oberen Extremität findet man ganz andere pathologische Verhältnisse. Die linke Hand ist nehmlich sebr abgemagert, die Spatia interossea eingefallen, Thenar und Antithenar abgeflacht. Am Vorderarm ist die Atrophie nur auffallend über dem Carpalgelenk, weniger in der Mitte und dem oberen Theile. Am Oberarm ist zwar eine Volumensabnahme nicht sichtbar, jedoch durcb Nessung des Umfanges und Vergleich mit dew der anderen Seite zu constatiren. Der Umfang des Oberarmes in der Mitte (Insertion des M. deltoides) ist nehmlich links 19,8, rechts $20,8 \mathrm{~cm}$ : am dicksten Theile des Vorderarms links 19,7 , rechts $20,7 \mathrm{~cm}$; an dessen dünnstem Theile (knapp oberhalb des Carpalgelenkes) links 13,5, rechts $15 \mathrm{~cm}$. Der Unterschied ist demnach zwischen rechts und links am Oberarm 1,0, am Vorderarm oben 1,0, unten $1,5 \mathrm{~cm}$. 
Die linke Hand wird in etwas adducirter Stellung gebalten, ঝ. h. gegen die Ulnarseite hin. Der Zeige- und Mittelfinger zeigen die Krallenform und führen mit Ausnahtne der von den Mm. flexores und dem Extensor digit. comm. abhängigen Bewegungen keine anderen aus. Der Ring- und kleine Finger führen noch einzelne von ibren $M m$. interossei abhängige Bewegungen in beschränktem Maasse aus. Der kleine Finger wird stets in abducirter Stellung gehalten und kann dem Ringfinger nicht genähert werden. Die Wirkung des Opponens ist auch sehr beschränkt. Der Daumen führt noch alle möglichen Bewegungen aus, jedoch mangelhaft und mit schwacber Kraft. Der Kranke ist kaum im Stande, eine Feder oder Nadel zu halten oder seine Kleider zuzuknöpfen u. s. w. Die kleinen Handmuskeln sind demnach theils ganz, theils hochgradig atrophisch. Unter den Muskeln des Vorderarms haben zumeist gelitten der Extensor und Flexor carpi radialis, weshalb die Hand in toto ulnarseits gehalten wird; an den übrigen Muskeln ist eine auffällige Störung nicht $\mathrm{zu}$ beobachten.

Dem Gesagten zufolge ist es erklärlich, warum Pat. mit der linken Hand trotz deren Atrophie im Ganzen and Grossen mehr mechanische Kraft zu entwickeln im Stande ist, als mit der nicht atrophischen, aber hemiparetischen rechten, warum er mit der linken Hand im Stande ist, eine Flasche Wasser zu heben oder den Regenschirm zu halten, während er all dies mit der rechten Hand nicht zu thun vermag. Bei allen diesen Thätigkeiten nehmlich kommen vornehmlich die Muskeln des Vorder- und Oberarms, sowie die der Schulter in Betracht, welche auf der linken Seite nur sehr wenig oder gar nicht gelitten haben, während alle diese Muskeln rechts paretisch sind. Anders verhält sich jedoch die Sache in Bezug auf die, mit den kleinen Handmuskeln auszuführenden feineren Handgriffe. Diese Muskeln sind links theils ganz, theils grossentheils geschwunden, während sie rechts trotz ihres paretischen Zustandes noch so viel Kraft besitzen, dass der Kranke mit ihrer Hülfe die Feder nicht nur halten, sondern auch führen, eine Nadel halten, die Kleider zuknöpfen kann u. s. w.

Es giebt aber ausserdem noch eine andere Ursache, weshalb Pat. mit der rechten Hand nicht so viel grobe mechanische Kraft auszuäben im Stande ist, als es vielleicht trotz seines paretischen Zustandes doch möglicb wäre. Er giebt nehmlich an, dass wenn er blos einen ganz leichten Stab in der rechten Hand trägt, seine Schmerzen sich im ganzen Arm so sehr steigern, dass er genöthigt sei, denselben in die linke Hand zu nehmen. Diese Erscheinung zeigt aber auch, dass die Schmerzen nicht allein in den sensiblen Aesten der Haut, sondern auch in denen der Muskeln sitzen, und dass sich dieselben bei der mindesten Anstrengung der Muskeln vermebren.

Fibrilläre Zuckungen waren zu der Zeit noch nirgends zu bemerken, sondern erst später, wie dies im Decursus morbi erwähnt werden wird. Die Sensibilität der Haut zeigt linkerseits keine Störung.

In Betreff der elektromusculären Reaction giebt zunächst der faradische Strom bei indirecter Reizung (N. ulnaris) sowohl rechts als 
links minimale Zuckung bei $9 \mathrm{~cm}$ Rollenabstand; es ist demnach die Reaction normal und sie besteht noch heute so. Bei directer Reizung zeigen die Muskelu des Ober- und Vorderarms sowobl rechts als links, sowie auch dje kleinen Handmuskeln rechterseits normale Reaction. Die kleinen Muskeln der linken Hand geben dem Grade ihrer Atrophie entsprechend bald noch normale, bald geringere, bald gar keine Reaction. So ist die faradische Reaction der $\mathrm{Mm}$. interossei des Zeige- und Mittelfingers $=0$, während der Abductor pollicis brevis, obwohl derselbe in Bezug des Volumens schon bedeutend ahgenommen hat, noch ziemlich gut functionirt und geradeso, wie der der rechten Hand, minimale Zuckungen bei $8 \mathrm{~cm}$ Rollenabstand zeigt.

Die Reaction gegen den galvanischen Strom ist bei indirecter Reizung ebenfalls rechts und links normal, insofern als vom N. ulnaris aus die minimale Zuckung schon bei 2 Milliampère auszulösen war. Bei directer Reizung jedoch ist dic Reaction auf der rechten (paretischen) Seite an den Muskeln des Ober-und Vorderarms eine entschieden geringere, als Jinkerseits. Ich habe mich hiervon unzähligemal nicht blos beim alltäglichen Elektrisiren, sondern auch mittelst galvanometrischer Messungen sowohl auf trocknem Wege als auch im elektrischen galvanischen Bade überzeugt. Bei der gewöhnlichen Messung zeigten die Muskeln der linken Seite minimale Zuckungen bei 2, die rechtsseitigen bei 2,5 Milliampère. In elektrischen Bade habe ich dies Verhältniss auf die Weise constatirt, dass wenn Pat. im monopolaren Anodenbade die mit der Kathode verbundene Querstange mit der linken Hand fasste, er bei Stromwendungen minimale Zuckungen im linken Arm schon bei 4 Elementen (Kohlenzink) verspürte, während, wenn er die Stange mit der rechten fland packte, er minimale Zuckungen erst bei 8 Elementen fühlte. Da wir es aut der rechten Seite, wie wir sehen werden, mit einer cerebralen Lähmung zu thun baben, und bei dieser die Reaction für beiderlei Stromes- und Reizungsarten eine normale zu sein pflegt, so bildet dieser Fall in der eben besprochenen Richtung eine übrigens nicht gar seltene Ausnahme.

Die Handmuskeln zeigen hier selbstrerständlich zwischen rechts und links geradedas umgekehrteVerhältniss, insofern als diejenigen linissseitigen Handmuskeln, welche hochgradig oder gänzlich atrophisch sind, im Verhältniss zu den rechtsseitigen entweder sebr verminderte oder gar keine Reaction geben.

Der Plantar- und Bauchreflex beiderseits $=0$, Cremasterreflex rechts $=0$, links sehr gering; Patellarreflex rechts etwas erhöht, links normal. Fussphänomen beiderseits $=0$.

I) Le Lunge zeigt geringen Katarm; ebenso ist die Schleimhaut des Rachens, Seblundes und Kehlkopfes katarhahisch afficirt. Der Herzstoss im 4. Intercostalraum zu fühlen; der erste Ton rein, der zweite an der Herzbasis accentuirt. Pulsfrequenz $z$ wischen $85-95$. Die fühlbaren Arterien fühlen sich weich an und sind leicht zusammendrückbar. Respiration 14-16. in der Minute; Temperatur normal. Die Leberdämpfung reicht, von der 4. Rippe bis 1 Plessimeter unterhalb des Rippenrandes; Milz ebenfalls etwas 
vergrössert. Appetit ziemlieh gut. Pat. litt auch vor seiner jetzigen Erkrankung schon an Obstipation, aber seit der Zeit hat er überbaupt ohne Abführmittel selbst in 8 Tagen keinen Stuhl; Geschlechtsfunction normal, keine Urinbeschwerden, Urin normal, Schlaf gut, wenn er nicht durch Husten gestört wird.

Der Kopf nicht schwer; Pat. hat auch jetzt noch oft Kopfschmerzen und Schwindel, aber doch seltener und gelinder, als vor dem Jahre 1880. Von den sogenannten Ohnmachtsanfällen wird weiter unten weit]äufiger gehandelt werden. Denk- und Erinnerungsvermögen gut; keine Spur von Sprachstörung; die Zunge wird gerade herausgestreckt, ohne zu zittern. Die Bewegungen der Lippen ganz frei (abgesehen von der geringen rechtsseitigen Facialisparese, wo die Schwäche in der Bewegung rechterseits erst beim Zeigen der Zähne hervortritt). Weder an den Lippen noch an der Zunge ist die geringste Spur von Atrophie zu sehen. Pat. spricht etwas heiser und näselt etwas. Vieles Sprechen und Vorlesen fällt ihm schwer, er fühlt dann eine Schwere auf der Brust und die Schmerzen vermehren sich im rechten Arm, verbreiten sich sogar oft auf die betreffende Brust- und Halsseite.

Wie schon oben erwähnt, ist das Schlingen auch jetzt noch manchmal trotz aller Vorsicht unvollständig, insofern als auch jetzt noch öfter bei der Suppe eine kleine Menge Flüssigkeit in die linke Nasenhöhle gelangt oder ein Bissen im Schlunde stecken bleibt, der dann zumejst auf einfache Anstrengung heruntergeht. Manchmal jedoch nützt eine solche Anstrengung des Schlingactes nicht, der Bissen bleibt noch weiter stecken; in solchen Fällen greift Pat. zu einem eigenthümlichen Manöver, mittelst dessen es ihm, wie er angiebt, gelingt, den steckengebliebenen Bissen doch herunterzubringen; er dreht nehmlich den Kopf stark von links nach rechts. Dies ist dadurch zu erklären, dass mit der Drebung des Kopfes, bezw. der Halswirbelsäule und mit dieser auch der weichen Halstheile von links nach rechts die letztgenannten Weichtheile gegen die rechtsseitige Schlundhälfte gepresst werden und dann in Folge angestrengterer Thätigkeit der linken Schlundhälfte der Bissen heruntergebracbt wird.

Der Kranke geht im Allgemeinen gut, oft $\frac{1}{2}$ Stunde, ohne zu ermüden. Die Ermüdung fühlt er stets zuerst im rechten Bein, in dessen Wade er äbrigens auch jetzt noch manchmal während des Gehens eine Spannung fühit und dessen Knie auch jetzt noch manchmal zusammenkippt.

Es erübrigt noch von den Ohnmachtanfällen zu sprechen. Diese Anfälle kamen noch vor der Erkrankung vom. Jahre 1880 und auch jetzt noch alljährlich 1-2mal vor, ohne dass jedoch jemals nacb einem solchen Lähmungen oder andere ernstere Folgen zuräckgeblieben wären, nur dass sich Pat. stets nach einem derartigen Anfalle 1-2 Tage sehr erschöpft fühlt. Als Gelegenheitsursache weiss Pat. manchmal nichts anzugeben, manchmal jedoch ist dieselbe sehr auffälig. So giebt er unter Anderem an, dass als er einmal von seinem Chef zu einem Gutsbesitzer auf's Land gescbickt wurde, der eine reichliche Mahlzeit serviren liess, er zwangsweise mehr Wein trinken musste, als er gewöhnt war; bei dieser Gelegenheit wurde ihm nach 
dem Speisen übel, er ward bewusstlos und fiel zusammen. Ein anderes Mal wurde er im Aborte im bewusstlosen Zustande gefunden, der ihn nach seiner Aussage in Folge starken Pressens befiel. Er war wahrscheinlich diesmal längere Zeit bewusstlos, als ein anderes Mal, wo er schnell mit Wasser bespritzt und ihm anderweitige Hülfe zu Theil wurde.

Seitdem Pat. unter meiner Beobachtung steht, hatte er schon zweinal solche Ohnmachtanfälle, nehmlich einmal im Jahre 1884 (März) und einmal im Jahre 1885 im Monat Febrnar. Den ersteren beschrieb Pat. folgendermaassen: Nachdem er Abends vom Gasthause nach Hause kam, fühlte er sich schlecht, bekam Uebelkeiten, wurde blass, bekam allgemeine Schwäche, es ward ihm dunkel vor den Augen, und er fiel endlich bewusstlos am Canapé, wo er sass, zusammen. Er wurde öfters mit Wasser bespritzt, bis er endlich allmäblich zu sich karn, aber er fühlte sich auch dann sehr hinfällig und wurde in's Bett gelegt. Obwohl er die ganze Nacht uuunterbrochen durchschlief, fühlte er sich noch am anderen Tage so scbwach, dass er ausser Stande war auszugehen; er konnte auch den ganzen Tag nichts zu sich nebmen, da er keinen Appetit hatte; erst am Abend vermoehte er etwas Abendbrod zu geniessen. Pat. behauptet, dass er bei diesen Anfällen nicht ganz das Bewusstsein verliere, dass er das Geschrei der um ihn Stehenden böre, und wisse, was man mit ibm vornehme, aber all das komme ibm so vor, wie wenn es im Traume geschähe; die Stimmen höre er so, als kämen sie aus der Ferne.

Da der eben beschriebene Anfall nach dem Nachtmahle kam, glaubte Pat., dass er sieh den Magen verdorben babe und dass der Anfall diesem Unstande zuzuschreiben sei. Indess hat es sich auf weiteres Befragen herausgestellt, dass Pat. am Abend zuvor (ror dem Page des Anfalles) auf einer Soirée war, wo er bis 1 Uhr nach Mitternacht blieb. Dies war meiner Meinung nach die eigentliche Ursache des Anfalles, wie ich dies weiter unten bei Besprechung der Diagnose weitläufiger begründen werde.

\section{Decursus morbi und Therapie.}

Bevor ich zur Diagnose übergehe, seien bier noch jene Veränderungen geschithert, welcbe ich von der Zeit der Aufnahme des Status praesens bis in die letate Zeit der Behandlung constatiren konnte. Von jener Zeit an (November 1883) bis Juli 1884 wurden Kopf und Wirbelsäule consequent galvanisch, die oberen Extremitäten aber zeitweise mit dem faradischen und zeitweise mit dem galvanischen Strome behandelt. Schon nach der erstmonatlichen Behandlung konnte Pat. wieder den kleinen Finger vollstäudig adduciren, und auch der Daumen konnte besser an den Zeigefinger angedrückt werden. Später konnte dann eive Volumens- und Kräftezunahme des linken Ober- und Vorderarmes constatirt werden. So zeigte die Messung des Umfanges in der Mitte des Oberarmes, am dicksten und dünnsten Theile des Vorderarmes rechts, nach der eben bezeichneten Reihenfolge der Theile: $21,0-21,0-15,2 \mathrm{~cm}$; links: $21,5-21,2-14,5 \mathrm{~cm}$. Es ist also zu ersehen, dass die Massenzunahme links eine viel stärkere 
war, als rechts, so dass während $7 \frac{1}{2}$ Monaten der linke Oberarm um 1,7, der Vorderarm oben um $\mathrm{d}, 5$, unten um $1 \mathrm{~cm}$ zugenommen hat, während in derselben Zeit die Zunahme rechts blos $0,2,0,3$ und $0,2 \mathrm{~cm}$, also in kaum in Betracht kommendem Maasse im Verhältniss zu links war, obgleich beide Arme stets gleichmässig sowobl mit dem faradischen als mit dem galvanischen Strom, und jedesmal gleich lange Zeit und mit derselben Stromintensität behandelt wurden. $\mathrm{Ja}$, die Sache gewinnt noch mehr an Interesse, wenn man das obige Zahlenverhältniss näher in's Auge fasst und daraus ersieht, dass der linke Arm, mit Ausnahme des Theiles unmittelbar oberbalb des Carpalgelenkes, nicht nur relativ an Umfang zunahw, sondern in Bezug desselben sogar den rechten etwas jubertraf.

Dem entsprechend hat auch die mechanische Kraft in der linken Hand mehr zugenommen als in der rechten, denn Pat. konnte zur Zeit der 2. Messung mit der linken Hand 13, mit der rechten blos 6 Kilo zusammendrücken. Alles dieses beweist nun zweierlei: 1) dass die elektrische Behandlung in solchen Körpertheilon, wo sich Störungen in der Ernährung zeigen, in eminentem Maase stoffersetzend wirkt, während in dieser Beziehung dieselbe Behandlungsweise, stets zu gleicher Zeit und in gleicher Weise ausgeführt, in einem anderen kranken Körpertheile, der aber normale oder doch nahezu normale trophische Verhältnisse aufweist, gar keine oder doch nur minimale stoffvermehrende Wirkungen zeigt. 2) zeigt das obige Zahlenverhältniss, dass der linke Arm wahrscheinlich vor Eintritt der Atrophie musculöser war als der rechte, indem er seit der Parese des rechten Arrwes, also mehrere Jahre hindurch, alle schwereren Arbeiten ausführen musste und demnach in einen Zustand sogen. Arbeitshypertrophie gerieth.

Vom Juli bis 16 . Noveraber 1884, also während $4 \frac{1}{2}$ Monate, sah ich den Kranken nicht. Wäbrend dieser Zeit wurde er nicht behandelt; nur brachte er 3 Wochen in Hof-Gastein zu, wo er aber nichts that, als dass er wöchentlich einmal ein laues Bad nahm. Als er im November wieder zu mir kam, konnte ich nicht nur eine Zunahme der Atrophio am linken Arm und an der linken Hand, sondern zugleich eine beginnende Atrophie auch im rechten (paretischen) Vorderarm und in der rechten Hand constatiren, und war die Atrophie des Thenar und im ersten Spatium interosseum dieser Hand selbst dem Kranken auffallend.

Ein anderes neues Phänomen, das sich jetzt zum ersten Mal zeigte, waren fibrilläre Zuckungen in den Muskeln des Daumens und Zeigefingers der linken Hand, die seitdem fortbestehen, aber bis jetzt noch kcinen anderen Muskel betroffen haben. Im November 1884 nahm ich wieder die elektrische Behandlung mit dem constanten Strom auf. Eine weitere Revision des Status im März 1885 zeigte im Vergleiche zum Status praesens (vom November 1883) folgende Veränderungen:

Die rechte Scapula steht fast gar nicht mehr von der Brustwand ab, 
die rechte Brustwarze liegt im Vergleiche zu früher weniger tiefer als die linke; von der rechtsseitigen Facialparese ist jede Spur geschwunden; ebenso jst der häufige Schwindel und der dadurch bedingte unsichere Gang seit $\frac{1}{2}$ Jahre gänzlich beseitigt. Der Kranke kann jetzt auch eine ganze Stunde lang promeniren, ohne Schwindel zu bekommen und ohne zu ermüden. Ueberraschend war aber selbst für den Pat. das gänzliche Schwinden der statischen Ataxie, die offenbar der Hemiparese der Stammmusculatur zugeschrieben werden musste. Alles dieses muss offenbar der consequenten galvanischen Behandlung des Kopfes und der Wirbelsäule (Gehirn und Rückenmark) zugeschrieben werden, da alle diese Symptome vordem fast 4 Jahre lang ununterbrochen bestanden haben. Dagegen ist in der sensiblen Sphäre sawohl in Bezug der Schmerzen als in Bezug der Anästhesie, sowie auch in Bezug der subjectiven und objectiven Symptome des Schlundes, Rachens und Kehlkopfes gar keine Veränderung, weder zum Besseren noch zum Schlimmeren, eingetreten. Endlich wäre noch zu erwähnen, dass auch der Husten und wit diesem die profuse Schleimexpectoration, sowie auch die hartnäckige Obstipation in letzterer Zeit sich bedeutend gebessert haben. Der Puls ist indess nach wie vor immer noch etwas beschleunigt.

\section{D i a g n o s e.}

Wenn wir nun die bis jetzt aufgezählten Erscheinungen nach den verschiedenen Zeiträumen, in denen sie aufgetreten sind, näher in Betracht ziehen, so lassen sich dieselben in 4 Gruppen theilen, die je einer verschiedenen Krankheitsepoche und je einem getrennten Krankheitsbilde entsprechen. Diese Erscheinungen sind ausserdem theils mehr oder weniger persistenter, theils progressiver Natur.

Die erste Gruppe von Krankheitserscheinungen, die schon seit 11 Jahren bestehen, aber sich in letzterer Zeit theilweise gebessert haben, besteht in Kopfschmerzen, Schwindel und sogenannten Ohnmachtanfällen. Zur zweiten "Gruppe gehören die durch Niesen hervorgerufenen Schmerzen und Parästhesien in der rechten oberen Extremität, der apoplektische Insult sammt der zurückgebliebenen rechtsseitigen motorischen, sensitiven und sensoriellen Lähmung, sowie das am Tàge der Apoplexie aufgetretene Schluchzen. Zur dritten Gruppe von Erscheinungen gehört die Lähmung der rechtsseitigen Hälfte des Pharynx, des weichen Gaumens und des rechten Stimmbandes; endlich zur vierten Gruppe die Muskelatrophie an der linken und später auch an der rechten oberen Extremität. Die Diagnose ist zwar in Bezug einzelner dieser Symptomencomplexe leicht, in Bezug anderer jedoch theils 


\section{8}

ziemlich schwer, theils in definitiver Weise kaum mit Sicherheit möglich.

a) Symptomencomplex der 1. Epoche: Hyperaemia maligna cerebri.

In dieser Symptomengruppe bilden jedenfalls die sogenannten Ohnmachtanfälle die hervorragendste Erscheinung, über deren Natur wir zu allererst in's Klare kommen müssen, da wir dann leicht die Bedeutung des ganzen Symptomencomplexes erkennen werden. Man könnte nun zu allernächst an epileptische oder epileptiforme Anfälle denken. Diese verlaufen aber gewöhnlich mit Convulsionen, die indess bei unserem Pat. niemals gesehen wurden. Diejenigen epileptiformen Anfülle aber, die ohne Krämpfe verlaufen, können wir im besten Falle erst dann als epileptische betrachten, wenn einzelne convulsivische oder wahre (typische) epileptische Anfälle intercurriren. Dergleichen Anfälle sind aber, wie erwähnt, bei unserem Pat. nie gesehen worden, und somit können die beobachteten Anfälle weder als epileptische noch als epileptiforme betrachtet werden.

Unter den übrigen paroxystischen Anfällen, die von den Laien als "Ohnmachten" bezeichnet werden, entspricht den bei unserem Kranken vorkommenden Zuständen am meisten das Bild des apoplektiformen Anfalles, indem auch bei ihm das Bewusstsein wohl schwindet, aber nicht gänzlich, wie dies sonst nur beim apoplektischen Insult der Fall ist. Die apoplektiformen Anfälle kommen bekanntlich hauptsächlich bei folgenden Hirnkrankheiten vor: a) gewisse bösartige Hirnhyporämien; b) Hirnsyphilis; c) progressive Paralyse; d) Atrophia und Encephalomalacia senilis; e) intracranielle Neoplasmen; f) Pachymeningitis haemorrhagica.

Nachdem die bei unserem Kranken vorkommenden Anfälle nicht als apoplektische zu betrachten sind, so können wir Hirnblutung und Hirnembolie ausschliessen. Die intracraniellen Geschwülste können ausgeschlossen werden, weil sie im Allgemeinen von kürzerer Dauer sind und mit intracraniellen Druckerscheinungen, wie Erbrechen, Stauungspapille u. s. w. verlaufen, die bei unserem Kranken gänzlich fehlen. Es kann ferner anch Hirnsyphilis ausgeschlossen 
werden, da einerseits der Kranke in Abrede stellt, jemals an Syphilis gelitten zu haben, andererseits kein auf diese hindeutendes Symptom zu constatiren ist, endlich angewendete Antisyphilitica, wie Jodkali und Sublimat, von keinerlei Erfolg waren. Von der progressiven Paralyse oder gar der Atrophie oder Encephalomalacia senilis kann in diesem Falle nicht einmal die Rede sein, ebenso wenig von der Pachymeningitis haemorrhagica, die ja fast ausschliesslich bei den zwei eben genannten Krankheitszuständen vorzukommen pflegt; es kann somit die Ursache der apoplektiformen Anfälle nur in einer Hirnhyperämie gesucht werden. Hierauf weisen übrigens auch die anderen Erscheinungen, wie die häufigen Kopfschmerzen and Schwindelanfälle, und dann ein gewisses ätiologisches Moment hin, welches ich erst in einer späteren Zeit von dem Kranken in Erfahrung brachte. Er gestand nehmlich, dass er früher ein leidenschaftlicher Kaffeetrinker war, indem er viermal täglich grosse Portionen starken Kaffees trank, und zwar zweimal Milchkaffee und zweimal schwarzen. Diese Kaffeediät wurde noch während der ganzen Zeit der ersten Erkrankungsperiode ununterbrochen fortgesetzt.

Die Hirnhyperämien werden bekanntlich in leichte und schwere eingetheilt. Die letzteren sind im Allgemeinen viel seltener und es gehören zu ihnen auch jene Formen, welche den Alten als apoplektische Congestionen - von den Franzosen als "Coup de sang" bezeichnet - bekannt waren. Zu diesen Formen gehört meiner Meinung nach der bei unserem Kranken beobachtete Zustand, dessen Zustandekommen wir uns zunächst so vorzustellen haben, dass sich bei dem Kranken unter den Erscheinungen von Kopfschmerzen und Schwindelanfällen ein hoher Grad von Status hyperaemicus ausbildete, der wohl an und für sich keine apoplektiformen Anfälle bedingt, sondern den Kranken blos zu solchen disponirt, wenn derartige Gelegenheitsursachen intercurriren, die eine plötzlich oder doch in kurzer Zeit allmählich auftretende neue, sei es active, sei es passive Congestion hervorrufen. Derartige Gelegenheitsursachen waren allerdings und sind überhaupt nicht immer in die Augen fallend; wir haben indess bei unserem Kranken 
mehrere derartige in die Augen springende Gelegenheitsursachen beim Zustandekommen der sog. Ohnmachtanfälle intercurriren gesehen. So z. B. Genuss von mehr Wein als gewöhnlich (active Congestion), oder starkes Drängen beim Stuhlabsetzen (passive Congestion). Alle diese Ursachen rufen indessen, wie wir wissen, unter gewöhnlichen Verhältnissen keineswegs apoplektiforme Anfälle hervor; und eben darum müssen wir bei unserem Kranken einen derartigen (malignen) Grad von Status hyperaemicus annehmen, der das Zustandekommen solcher Anfälle auch schon bei Concurrenz geringerer Grade von neuen Congestionen ermöglicht.

Uebrigens sind es nicht blos plötzlich oder in relativ kurzer Zeit allmählich zu Stande kommende Congestionen, die bei solchen Graden von Status hyperaemicus apoplektiforme Anfälle hervorrufen, sondern es können auch jenen gerade entgegengesetzte Zustände, nebmlich plötzlich oder in relativ kurzer Zeit allmählich zu Stande kommende Anämien eben so gut als gelegentliche Ursachen solcher apoplektiformen Anfälle gelten; sowie denn überhaupt allgemein bekannt ist, dass die Hirnanämie ganz dieselben Erscheinungen, wie die Hirnhyperämie, hervorzurufen im Stande ist. Jene ist ebenso, wie diese, von Schwindel, Kopfschmerzen u. s. w. begleitet. Die böheren Grade von Anämie können eben so gut bald einfache Syncope, bald apoplektiforme Zustände hervorrufen, wie die böheren Grade von Hirnbyperämie.

Derartige Gelegenheitsursachen, welche plötzlich oder in relativ kurzer Zeit allmählich zu Stande kommende Hirnanämie und in Folge dieser apoplektiforme Anfälle hervorrufen können, haben auch bei unserem Kranken nicht gefehlt. Als eine derartige Gelegenheitsursache muss meiner Meinung nach in Betreff des schon oben beschriebenen vorjährigen apoplektiformen Anfalles der Excess des längeren Nachtwachens am Abend vorher, und die dadurch entstandene Erschöpfung, bezw. relative Anämie aufgefasst werden. Aber noch mehr ist hierher zu rechnen der im letzten Jahre (1885) vorgekommene apoplektiforme Anfall, dessen Geschichte die folgende ist: Der Kranke nahm auf meine Verordnung gegen seine Obstipation 2 Stiick $0,07 \mathrm{mg}$ Podophyllinpillen, eine am 
A bend, die andere am anderen Morgen früh. Hierauf hatte Pat. den ganzen Tag keinen Stuhl, aber am Abend hatte er im Zeitraume von $\frac{1}{2}$ Stunde 3 mal diarrhoischen Stuhl, was ihn so geschwächt hatte, dass, als er vom 3. Stuhlgange in's Zimmer trat, er ohnmächtig wurde und niederfiel. Hier kann demnach kein $Z$ weifel daräber sein, dass die in kurzer Zeit zu Stande gekommene relative Anämie den apoplektiformen Anfall hervorief.

Die Erklärung aller dieser Erscheinungen besteht in Folgendem: Das Gehirn ist im gesunden Zustande an einen gewissen Grad von Blutfülle der Gefässe gewöhnt, vermöge deren dasselbe fähig ist, selbst hochgradige Schwankungen sowohl gegen das Plus als gegen das Minus hin ohne irgend welche Functionsstörung zu ertragen. Wenn aber auch hier in der Circulation eine plötzlich eintretende Schwankung eine gewisse Grenze überschreitet, so können auch bei einem, innerhalb physiologischer Grenzen mit Blat versehenen Gehirne schwere Symptome, ja sogar der plötzliche Tod eintreten. Hierher gehören bekanntlich die Fälle, wo auf grosse Gemüthserschütterungen plötzlicher Tod eintritt. Von einem solchen Falle habe ich erst unlängst ein drastisches Beispiel in den Zeitungen gelesen. Ein junger Mann kam nehmlich in einer hiesigen Kaserne zur Rekrutirung, und als die Rekrutirungs-Commission das Wort "tauglich" aussprach, fiel derselbe vor Schreck um, und blieb sogleich todt liegen. (Polizeiärztlich constatirt.)

Das sind natürlich höchst seltene und aussergewöhnliche Fälle, die aber nur beweisen, welche schwere Veränderungen durch den sogenannten Shock auch im normal bluthaltigen Gehirne vorkommen können. Indess gewöhnt sich das Gehírn bei seinem grossen Accommodationsvermögen an langsam entstehende Hyperämien und Anämien in der Weise, dass diese Zustände, auch wenn sie persistiren, unter normalen Verbältnissen ohne besondere Störungen ertragen werden; jedoch werden hier schon die kleinsten Schwankungen in der Circulation sowohl gegen das Plus als gegen das Minus hin pathologische Erscheinungen, wie Kopfschmerzen, Schwindel u. s. w., grössere Schwankungen aber auch syncopeartige oder auch apoplektiforme Anfälle hervorrufen: wohl gemerkt, solche Grade 
von Schwankungen, welche unter physiologischen Verhältnissen höchstens Kopfschmerzen geringeren oder höheren Grades hervorzurufen im Stande sind.

Um dies mit einem ebenfalls aus dem Leben unseres Pat. entnommenen Beispiele zu beleuchten, will ich wieder auf jene Episode rurïckkommen, wo der Kranke nach lange durchwachter Nacht am folgenden Abend einen apoplektiformen Anfall bekam. Ein gesunder, d. h. mit physiologischer Hirncirculation versehener Mensch fühlt höchstens am Tage nach einer lange durchwachten Nacht Kopfschmerzen, oder or fühlt sich am Abend nach vollendeter Tagesarbeit müder und schläfriger als sonst, mit einem Worte das, was man mit profanem Ausdrucke "Katzenjammer" nennt. Unser Pat. hingegen, der an einem schweren Grade von Status hyperaemicus leidet, war nach der länger durchwachten Nacht in Folge der sich dadurch einstellenden relativen Anämie nach vollendeter Tagesarbeit so sehr erschöpft, dass er einen Ohnmachtanfall bekam.

Was die Aetiologie dieser malignen Hirnhyperämie betrifft, so ist dieselbe, wie schon oben erwähnt, am wahrscheinlichsten durch den viele Jahre hindurch gepflegten häufigen Genuss starken Kaffees hervorgerufen worden, wobei auch die schwache Constitution und die neuropathische Belastung des Kranken jedenfalls das ihrige zur Entstehung des Leidens beigetragen haben dürften.

b) Zweite Krankheitsepoche. - Haemorrhagia cerebri.

Die zweite Krankheitsepoche hat, wie wir gesehen haben, damit begonnen, dass Pat. in Folge eines Nieseactes Ameisenkriechen und Schmerzen in der rechten Hand bekam. Diese Erscheinung ist nur durch eine an irgend einem Punkte der linksseitigen sensiblen Bahn des Gehirns entstandene capilläre Apoplexie zu erklären; der am nächsten Tage Morgens eingetretene apoplektische Insult dagegen durch eine massigere, sogen. vasculäre Hirnblutung. Nachdem nun aber in Folge dieser letzteren Blutung die Schmerzen in der rechten oberen Extremität sowohl an In- als Extensität zugenommen haben, kann mit ziemlicher Sicherheit angenommen werden, dass die vasculäre Blutung, die zugleich eine rechtsseitige motorische und 
sensible Lähmung hervorrief, an demselben Orte, oder wenigstens in nächster Nachbarschaft desselben geschehen sein musste, wo die capilläre Blutung localisirt war. Mit anderen Worten, die massenhaftere Blutung war mit grösster Wahrscheinlichkeit nur die Fortsetzung der capillären Blutung. Wenn die capilläre Blutung allein für sich geblieben wäre (ohne nachfolgende vasculäre Blutung), so hätte man den Ort der Läsion nicht genau localisiren können, da derselbe ebenso gut in den hinteren Theil des linken Centrum semiovale, als auch in das hintere Drittel der hinteren Hälfte der Capsula interna oder in den linken Hirnschenkel, den Pons oder dic Medulla oblongata hätte verlegt werden können.

Nachdem wir aber mit ziemlicher Bestimmtheit sagen können, dass die grössere Blutung nur die Fortsetzung der capillären war, so müssen wir vice versa die letztere dorthin verlegen, wohin wir die die Hemiplegie verursachende grössere Blutung localisiren können. In Bezug dieser letzteren ist aber die Localisation nicht schwer, da wir wissen, dass derartige halbseitige motorische Lähmungen, die nicht blos mit sensibler, sondern zugleich mit sensorieller Lähmung gepart sind, mit der grössten Wahrscheinlichkeit in letzten Drittel der hinteren Hälfte der Capsula interna localisirt werden können, dorthin nehmlich, wo das Charcot'sche Carfour sensitif mit der Flechsig'schen Pyramidenbahn zusammentrifft; somit müssen wir die capillare Blutung auch dahin localisiren, mit dem Unterschied jedoch, dass diese noch ganz allein in das Carfour sensitif fällt. Ueberdies müssen wir noch hinzusetzen, dass das Carfour sensitif selbst durch dievasculäre Blutung noch stärker getroffen wurde, als die Pyramidenbahn, da die Anästhesie im Allgemeinen viel stärker ausgeprägt und auch weiter verbreitet ist, als die motorische Lähmung, die ja selbst in ihren intensivsten Graden blos eine Parese ist.

Wenn wir nun die verschiedenen Grade der sensiblen und motorischen Lähmung in den verschiedenen Körpertheilen näher in's Auge fassen und mit einander vergleichen, so köunen wir gewisse Folgerungen in Bezug der Vertheilung und gegenseitigen Lage der jenen Körpertheilen entsprechenden sensiblen und motorischen Faserzüge an diesem Begegnungsorte 
der sensiblen und motorischen Bahnen im Gehirne ableiten. Im Status praesens haben wir nehmlich gesehen, dass die obere Extremität und der Stamm sowohl von der sensiblen als von der motorischen Lähmung zumeis t getroffen wurden. Von der motorischen lähmung der unteren Extremität war objectiv keine Spur mehr aufzufinden, während die sensible Lähmung noch ganz rein vorhanden war, jedoch nur bis zu den Knöcheln, während unterhalb dieser die Sensibilität eine ganz normale war. Von dieser Zone nach aufwärts nimmt die Sensibilitätslähmung an dieser Fxtremität gradatim zu. Im Gesicht ist die motorische Lähmung schon deutlich ausgesprochen, jedoch nicht so stark, wie an der oberen Extremität und am Stamm; auch die Anästhesie ist hier nicht so stark ausgeprägt, wie an den letztgenannten Theilen und am Halse, mit Ausnahme der mit der Gesichtshaut in Verbindung stehenden Schleimbäute, an denen die Anästhesie wieder stärker ist, als an dẹr Gesichtshaut (wahrscheinlich wegen anderer Beschaffenheit und zarterem Baue ihrer Endigungen und der diese bedeckenden Epithelschicht).

Wenn wir alles das in Betracht ziehen, so können wir als wahrscheinlich aussagen, dass im hintersten Theile der Capsula interna, wo beide Bahnen neben einander liegen, und wahrscheinlich auch noch im ganzen Verlaufe des Fusses der Hirnschenkel, die sensiblen und motorischen Faserzüge der oberen Extremität, des Halses und des Stammes unmittelbar an einander liegen, respective die medialen Theile der neben einander liegenden beiden Bahnen bilden. $V_{\text {on }}$ da aus nach aussen kämen die Faserzüge des Gesichts (und seiner Höhlen) - die sensiblen Züge in der sensiblen, die motorischen in der motorischen Bahn. Endlich am weitesten von einander entfernt kämen in den beiden Faserlagen die Faserzüge der unteren Extremität zu liegen. Ja, wir könnten vielleicht noch weiter in unserer Folgerung gehen and sagen, dass die Faserzüge der unteren Extremität unter einander wieder so angeordnet sind, dass die des Fusses mehr peripherwärts liegen, als diejenigen des Unter-, bezw. Oberschenkels.

Wir können uns demnach den Vorgang im Gehirn folgendermaassen vorstellen: Die Capillarapoplexie ist in der sensiblen Bahn in den Faserzügen der oberen Extremität, 
demnach in dem medialen Theil dieser Bahn vor sich gegangen. Die darauf gefolgte vasculäre Blutung, wahrscheinlich von demselben Heerde ausgehend, ist von da aus in den medialen Theil der Pyramidenbahn gedrungen, so dass die an dem peripherischen Theile dieser Bahn liegenden Faserzüge (der unteren Extremität) fast unberührt geblieben sind und höchstens durch Fernwirkung in Mitleidenschaft gezogen wurden. Anders in der sensiblen Bahn. Hier sind noch selbst die (äusseren) Faserzüge der unteren Extremität unmittelbar getroffen worden, jedoch blos bis zu denen des Fusses, die auch hier intact goblieben sind. Der Blutheerd bat demnach beide Bahnen getroffen. Der Mittelpunkt des Heerdes war aber die mediale Partie der sensiblen Bahn, welche Bahn eben darum stärker befallen wurde, und es ist die Blutmasse in dieser weiter peripheriewärts gedrungen als in der motorischen, was eben die Ursache ist, dass die sensible Lähmung intensiver und extensiver wurde, als die motorische.

In Bezug der Ursache der Hirnblutung wissen wir, dass letztere, wie uns die Untersuchungen von Charcot und Bouchard lehrten, durch Entwickelung von Miliaraneurysmen der kleineren Gefässe des Gehirns bedingt ist. Zur Entwickelung solcher Miliaraneurysmen war aber bei unserem Kranken genügende Gelegenheit gegeben durch die, während eịner langen Reihe von Jahren bestandene, schwere Hirnhyperämie, wie wir dies oben sahen. Dieser Umstand erklärt es auch, warum die Hirnhämorrbagie bei unserem Pat. schon in einem früheren Lebensalter, als dies gewöhnlich geschieht, eingetreten ist.

In Betreff der Grösse des Blutheerdes können wir aus dem Umstande, dass der apoplektische Insult von relativ kurzer Dauer war, dass der Kranke gleich nach demselben aufstehen konnte, sich ankleidete und vom Hause wegging, und endlich daraus, dass die motorische Lähmung, wenn auch persistent, doch nur eine Parese ist, auf einen kleinen Heerd schliessen. Andererseits trifft aber gerade bei unserem Patienten die Eigenthümlichkeit zu, dass trotz geringfügiger Blutung ein so schweres Phänomen, wie der apoplektische Insult, eingetreten ist, im Gegensatze zu jenen selteneren Fällen, wo den klinischen 
Symptomen nach zu urtheilen, man auf einen grossen Blutheerd zu schliessen berechtigt ist, ohne dass es doch zu einem apoplektischen Insult überhaupt kommt. Die Kranken verlieren dabei nicht einen Moment die Besinnung, sondern, wie sich Heubner ausdrückt, sie können die Lähmung ihrer Glieder von Schritt zu Schritt verfolgen. Als Pendant zu dem Kranken Sch. K. will ich einen Fall der letzten Kategorie mittheilen, den ich unlängst Gelegenheit hatte zu beobachten, und dessen Krankengeschichte ich, damit keine Unterbrechung in der des Sch. K. eintrete, weiter unten (im II. Abschnitte dieses Aufsatzes) mittheilen will. Dieser Fall ist übrigens auch noch insofern von Interesse, als auch hier das betroffene Individuum noch verhältnissmässig jung war und sich unter den Symptomen eines vorfindet, das bei cerebralen Hämorrhagien sehr selten ist.

c) und d) Symptome der 3. und 4. Krankheitsepoche.

Was die Symptome der 3. Epoche anlangt, so sahen wir, dass 1 Jahr nach Eintritt der cerebralen Blutung sich allmählich und langsam innerhalb 6 Tagen eine Lähmung der rechten Hälfte des Gaumensegels, der rechten Schlundhälfte und des rechten Stimmbandes einstellte: Diese Lähmung war anfangs hochgradig, hat. sich jedoch im Verlaufe einiger Wochen bis auf einen gewissen Grad gebessert, auf welchem sie sich auch heute noch befindet.

Diese Besserung ist aber blos eine scheinbare, insofern als die Function dieser Organe zwar theils eine normale, theils eine leidlich gute geworden ist, jedoch die betreffenden Theile, wie zu Anfang, total oder fast total gelähmt sind. So zeigt die Kehlkopfspiegeluntersuchung, dass das rechte Stimmband auch jetzt noch total bewegungslos ist, obwohl die Heiserkeit nur eine mässige ist, während sie in der ersten Zeit eine totale war, so dass der Kranke nur eine Lispelstimme hatte. Ebenso zeigt die rechte Schlundhälfte nicht die mindeste Beweglichkeit, weder auf mechanische noch auf elektrische Reizung. Die rechte Hälfte des weichen Gaumens zeigt zwar eine minimale. Beweglichkeit, aber dieselbe würde keineswegs ausreichen, die obere Rachenhälfte von der unteren abzuschliessen, wenn nicht die linksseitige 
Gaumensegelhälfte vicariirend eingriffe, indem durch deren kraftvollere Thätigkeit auch die rechte Segelhälfte gespannt wird. Noch mehr muss aber diese vicariirende Thätigkeit für die linke Schlundseite beansprucht werden, insofern als die kraftvollere Thätigkeit derselben die mangelnde Thätigkeit der rechten Hälfte ersetzt. Diese vicariirende Thätigkeit lässt sich am schönsten demonstriren im Kehlkopf. Die Spiegeluntersuchung zeigt nehmlich, dass trotz totaler Unbeweglichkeit des rechten Stimmbandes die Stimmritze sich vollständig schliesst, und zwar in der Art, dass das linke Stimmband nicht blos bis zur Mittellinie, sondern weit über dieselbe hinaus gezogen wird, so dass es vicht blos den Rand des gelähmten Stimmbandes berührt, sondern noch etwas über denselben hinübergeht und ihn noch etwas be$\operatorname{deckt}^{1}$ ).

Nach alledem ist leicht zu verstehen, wie es kommt, dass trotz vollständiger Lähmung der rechten Schlundseite der Kranke

1) Diese kräftigere oder compensatorische Thätigkeit der gesunden Seite des Larynx, Pharynx und Velum pal. ist offenbar nur durch eine langsam sich entwickelnde Hypertrophie der betreffenden Muskeln zu erklären. Die Furcht vor Erstickung durch den Bissen bat den Kranken instinctmässig daza gezwungen, dass er die linke Schlundseite behufs Befreiung rom Bissen mehr anstrenge, was endlicb zur geweblichen Hypertrophie dieser Muskeln geführt hat. Dasselbe gilt von den die Schliessung der Stimmritze bewirkenden linksseitigen Muskeln des Kehlkopfes. Alles dies beweist sehr schön, wie die Natur sich in der lebenden Welt den verscbiedenen Umständen anzupassen vermag, und wie sich in specie der thierische Organismus nicht nur den äusseren (klimatischen u. s. w.), sondern auch ten in Inneren des Organismus vorkommenden neuen und pathologisch veränderten Verhältnissen anzupassen im Stande ist. Ueber diesen Gegenstand hat Notbnagel unlängst einen interessanten Vortrag in der Wiener Gesellsch. der Aerzte (Sitzung vom 12.Juni 1885) unter dem Titel „Ueber compensatorische Muskelhypertrophie" gebalten, in welchem er besonders auf die bekannten compensatorischen Hypertrophien der Gedärme und des Herzens hinweist. Weniger bekannt dürfte die eben bei unserem Kranken beschriebene compensatorische Hypertrophie der. Kehlkopf-, Schlund-und Gaumensegelmuskeln sein, und es dürften demnach diese Erscheinungen als werthvolle Beiträge zu den von Nothnagel besprochenen compensatorischen Muskelbypertrophien gelten, 


\section{8}

dennoch gut schlucken kann, und dass trotz fast vollständiger Lähmung der rechten Gaumensegelhälfte nur sehr selten noch Flïssigkeit durch die Nase tritt und der Kranke nur noch sehr wenig durch die Nase spricht. Eine Erscheinung ist mir jedoch noch jetzt ganz unverständlich, nehmlich dass die Flüssigkeiten (wenn sie auch jetzt noch hie und da durch die Nase heraustreten) stets nur durch die linke Nasenhälfte herauskommen, während dies doch, da die rechte Choane von der unteren Rachenhälfte mangelhaft abgeschlossen wird, umgekehrt sein sollte.

Die rechtsseitige Anästhesie, die sich auch auf die Nasenhöhle erstreckt, könnte höchstens die Ursache dafür sein, dass dor Kranke, wenn Flüssigkeit in die rechte Nasenhöhle käme, dieselbe nicht fühlte, und im Falle, dass die Flüssigkeit durch beide Nasenhälften herauskäme, er dieselbe blos in der linken Nasenhälfte wahrnähme, gerade so, wie sich dies im Schlunde verhält. Der Kranke behauptet nehmlich in Betreff eines hie und da noch immer im Schlunde stecken bleibenden Bissens, dass dieser nie in der rechten, sondern stets in der linken Seite des Schlundes stecken bleibe, wo doch das an und für sich ein Nonsens ist, da der Bissen eher in der rechten Hälfte stecken bleiben müsste und zwar wegen Lähmung und Schlaffheit der entsprechenden Muskelschicht. Da aber die Schleimhaut der rechten Schlundhälfte vollständig anästhetisch ist, der Kranke demnach den Bissen blos mittelst der linken Hälfte empfindet, so hat er den Eindruck, als wäre derselbe blos in der linken Hälfte stecken geblieben. Bei der Nase kanu indess keine Täuschung vorliegen, da der Kranke entschieden behauptet, dass Flüssigkeit blos aus einem Nasenloch, und zwar stets nur aus dem linken herausgekommen sei und auch jetzt noch herauszukommen pflege.

Der hochgradigen Lähmung aller dieser rechtsseitigen Organtheile gemäss fehlen in ihnen auch die Reflexe gegen jedwede sei es mechanische, sei es elektrische Reizung. Wie man immer diese Theile reizen mag, man ist nicht im Stande, sei es Schlingbewegung, sei es Brechreiz oder Thränenabsonderung auszulösen. Was die eigentliche Anästhesie (tactile und electrocutane) betrifft, so gehört diese Affection eigentlich nicht hieher, sondern ist als Theilerscheinung der rechtsseitigen Hemianästhesie anzusehen. 
Der einige Zeit nach Eintritt dieser Lähmungen aufgetretene Husten und Bronchialkatarrh, der aber in Ietzterer Zeit bedeutend abgenommen hat, ist meiner Meinung nach der Anästhesie und dem Mangel an Reflexen der rechtsseitigen Kehlkopf- und Bronchialschleimhäute zuzuschreiben und demnach als auf neuropathologischer Basis beruhend zu betrachten. Der schnelle Puls dürfte auf Affection eines Theiles des rechten $\mathrm{Va}$ guskernes beruhen.

Die Frage über den Sitz des Heerdes muss zunächst dahin beantwortet werden, dass wir es mit einer einseitigen und zwar rechtsseitigen circumscripten Affection der Medulla oblongata $z u$ thun haben. Den Symptomen nach kommt zunächst eine Affection des oberen Accessoriuskernes (Vagoaccessoriuskernes) in Betracht. In weiterer Beziehung sind es die sogenannten inneren Zweige des Facialis, bezw. der sogen. untere Facialiskern, die mit afficirt sind. Insofern endlich, als auch die grössere Pulsfrequenz von einer wenigstens theilweisen Erkrankung des Vagus abhängen dürfte, kann als wahrscheinlich angenommen werden, dass auch dieser Nervenkern rechterseits theilweise mitergriffen sei.

Eine weitere Frage ist nun die, welcher Natur diese Affection der Medulla oblongata möglicherweise sein könnte, und in welche Kategorie von Krankheitsprozessen dieselbe einzureihen ist?

Der Umstand, dass die Affection selbst nach 4jährigem Bestande auf einen kleinen Heerd beschränkt geblieben ist, weist zunächst darauf hin, dass der Prozess kein progressiver ist. Dieser Umstand, sowie das Bestehen der Krankheit auf einer Seite, schliesst um so mehr die typische Bulbärparalyse aus, als bei dieser die Lähmung der Zunge und der Lippen zu den ersten und dominirenden Symptomen gehören, während sie bei unserem Kranken vollständig fehlt.

Es ist anzunehmen, dass sich jetzt im verlängerten Marke ein abgelaufener Prozess befindet, dass namentlich rechterseits entsprechend den obengenannten Nervenkernen, also am untersten Ende der Fossa rhomboides - bis in die Gegend des Calamus. scriptorius reichend - ein sclerotischer Heerd (Narbe) sitzt, der wahrscheinlich seinen Ausgangspunkt von einem in subacuter Weise begonnenen Erweichungsprozesse genommen hat. Ueber 
die Natur dieses Erweichungsprozesses lässt sich jedoch schwer etwas Bestimmtes aussagen. Da die Heerdsymptome sich ohne jede allgemeine Erscheinungen in subacuter Weise (innerhalb 6 Tagen) entwickelten, so wäre an eine genuine subacute poliencephalitische - Entzündung, oder an eine auf die kleine Region beschränkte Capillarapoplexie oder Thrombose der die betreffenden Kerne versorgenden kleinen Arterien zu denken.

Nachdem Leyden eine acute Form der Poliencephalitis inferior und Wernicke eine solche der Poliencephalitis superior') beschrieb, so wäre auch die Annahme nicht ganz ungerechtfertigt, dass bei unserem Kranken das verlängerte Mark in Folge einer gewissen Schädlichkeit von einer genuinen circumscripten subacuten Entzündung befallen worden sei. Verlockender wäre freilich die Annahme einer syphilitischen (thrombotischen). Erweichung, um so mehr, da überhaupt das Gesammtbild der ersten 3 Erkrankungsperioden in vieler Beziehung an das so bunte und wechselreiche Bild der Hirnsyphilis erinnert. Nachdem wir aber weiter oben bereits die Syphilis ausgeschlossen haben, so kann sie auch hier weiter nicht in Betracht kommen.

Man könnte sich aber die Sache auch so denken, dass der Prozess mit einer Capillarapoplexie begonnen habe, die wegen Kleinheit des Heerdes ohne jede Allgemeinerscheinungen zu Stande kam. Wenn aber auch bei dem Kranken Kopfschmerzen (etwa im Hinterhaupte) und Schwindel intercurrirt

1) Nachłlem StrümpelI (Wiener Medic. Blätter 1884) unter dem Namen Poliencephalitis infantum einen bei Kindern im grauen Hirnmantel vorkommenden acut entzündlichen Prozess beschrieben hat, so wäre eigentlich die Benennung Poliencephalitis superior für diese Erkrankung passender, als für die der Kerne der motorischen Augennerven, von der wir auch schon, wie oben erwähnt, eine acute Form kennen. Es wäre demnach wünsehenswerth, wenn bier einfachere und klarere Benennungen geschaffen würden. Meiner Meinung nach wäre die Strümpell'sche Poliencephalitis infantum Poliencephalitis corticalis acuta zu benennen (der chronische Prozess bei der Dementia paralytica als Poliencephalitis cork. chronica); dann die Poliencephalitis superior acuta (Wernicke) und chronica (Ophthalmoplegia progr. chron.) als Poliencephalitis oculonuclearis acuta und chronica; endlich die Leyden'sche Poliencephalitis inferior acuta, sowie die chronische Form, nehmlich die progressive Bulbärparalyse, als Poliencephalitis bulbaris acuta und chronica zu bezeichnen. 
haben . mochten, so wurden diese von ihm gewiss nicht in Betracht gezogen oder vergessen, da er seit Jahren an diese Symptome gewöhnt war. Die Capillarapoplexie hätte eine subacut verlaufende (reactive) Entziundung zur Folge gehabt, die später in ein chronisches Stadium überging und zur Sclerose führte. Dieser Krankheitsprozess entspräche noch am besten den gegebenen intracraniellen Verhältnissen bei unserem Kranken, da einerseits ein Jahr vorher ebenfalls Hämorrhagie und als Vorläufer sogar auch Capillarapoplexie in einem anderen Hirntheile zu Stande kam, andererseits aber die der Apoplexie zu Grunde liegende Ursache, nehmlich Miliaraneurysmen kleinster Arterien, sowie die das Zustandekommen dieser begünstigende Hirnhyperämie als auch in der Medulla oblongata bestehend vorausgesetzt werden darf.

In Betreff der Symptomatologie der Capillarapoplexien in der Medulla oblongata lassen sich keine bestimmten Anhaltspunkte in der Literatur auffinden. Jedenfalls lässt sich denken, dass höchstens auf 1-2 Nervenkerne beschränkt gebliebene Capillarapoplexien in der Medulla oblongata (wenn es nur nicht der Vaguskern in toto ist), ohne acute Erscheinungen zu Stande kommen könnten. Erb spricht sich in dieser Beziehung in seinem Werke über Rückenmarkskrankheiten ${ }^{1}$ ) ebenfalls unbestimmt aus. Er sagt nehmlich daselbst (S. 878) Folgendes: "Ueber die Symptome der kleinen capillaren Apoplexien der Oblongata ist nicht viel bekannt. Sie dürften ungefähr dieselben sein, wie die der Embolien kleinster Arterien im Bulbus, und nur bei erheblicher Ausdehnung sich deutlich bemerkbar machen." Und in Betreff der Embolien kleiner Arterien heisst es ebendaselbst (S. 888) folgendermaassen: „Eine Verstopfung der kleinen Gefässstämmchen des Bulbus wird wohl selten an ihren Symptomen mit Sicherheit erkannt. Da diese Arterien aber meist Endarterien sind, wird ihre Obliteration jedenfalls von vernichtenden Folgen für die Function der jeweils getroffenen Theile sein, und es kommt blos anf den Verbreitungsbezirk einer solchen Arterie an, ob sich Symptome zeigen."

Diese Schilderung passt nun ganz auf die bei unserem Kranken gemachten Beobachtungen, indem bei ihm andere, als

1) Ziemssen's Specielle Path. und Ther. Bd. XI. 2. Bälfte. 
reine Heerdsymptome, die aus der allmählichen Vernichtung der betroffenen Kerne hervorgegangen sind, angeblich nicht vorkamen. Nach alledem zu schliessen, dürfte es demnach am wahrscheinlichsten sein, dass wir es ursprünglich mit einer Capillarapoplexie im Bulbus zu thun hatten.

Nun haben wir noch in Betracht zu ziehen, dass $1 \frac{1}{2}$ Jahre nach Entwicklung der bulbären Symptome (4. Krankheitsepoche) sich zu diesen die der typischen progressiven Muskelatrophie hinzugesellten. Das Auftreten der letzteren Krankheit möchte ich nicht als "zufällige" Complication des gesammten, von unserem Kranken dargebotenen Krankheitsbildes, sondern als in demselben Connex mit der circumscripten Sclerose im Bulbus stehend betrachten, wie etwa die typische progressive Bulbärparalyse sich häufig mit der Poliomyelitis anterior chronica combinirt: Es würde alsdann unser. Fall ein Beweis dafür sein, dass sich nicht blos die von vorneherein chronisch beginnende (sclerctisirende) progressive Poliencephalitis inferior (bulbaris), sondern auch aus directen Erweichungsheerden hervorgegangene circumscripte sclerotische Prozesse im Bulbus mit progressiver Muskelatrophie combiniren können.

Wir haben weiter oben die bulbäre Affection als mit der ein Jahr vorher eingetretenen Hirnläsion gleichwerthig hingestellt, insofern als beide Läsionen auf gleiche ursächliche Momente (Miliaraneurysmen) zurückzuführen seien. Es wäre indess auch die Frage zu ventiliren, ob nicht etwa die bulbäre Affection in einem ähnlichen ursächlichen Connex zu der Grosshirnläsion stehe, wie die spinale Affection zur bulbären. Wenn wir diese Frage bejahen wollten, so könnte man nur an einen Fall denken, nehmlich an die secundäre Degeneration der Pyramidenbahn, die doch auch gewiss in unserem Falle in Folge der Hämorrhagie in dem hintersten Theile der inneren Kapsel vorhauden ist, wenn auch die rechtsseitige Lähmung eine schlaffe ist. Man müsste sich nun die Sache so denken, dass indem sich die secundäre Degeneration auch auf die Pyramiden erstreckt, sich in Anschluss daran in dem über denselben befindlichen subependymatischen Gewebe, bezw. in den in unserem Falle afficirten Nervenkernen ein Erweichungsheerd bildete, ebenso wie sich im Rückenmarke im Anschluss an die secundäre Degeneration 
der Pyramidenbahnen myelitische Heerde entwickeln können [Charcot $\left.\left.{ }^{1}\right)\right]$.

Man könnte sich dann den Prozess auf die Weise zu Stande gekommen denken, dass jene feineren $Z$ weige der Art. spinalis anterior, welche durch die degenerirten, sclerotisch geschrumpften Pyramidenbünde] zu den über denselben gelegenen Nervenkernen verlaufen, mit in den sclerotischen Prozess einbezogen wurden, obliterirten, und so zur thrombotischen Erweichung des betreffenden subependymatischen Gewebes Anlass gaben. Uebrigens sind Befunde von circumscripten sclerotischen Heerden (Narben) im untersten Winkel der Rautengrube entsprechend der Gegend des Calamus scriptorius, also ganz genau an derselben Stelle, wie wir sie bei unserem Kranken anzunehmen haben, gar nicht selten. Unter Anderen hat Eisenlohr in einem Falle eine derartige Sclerose am Boden des 4. Ventrikels gefunden, die durch Verstopfung der"Art. vertebralis und ibrer Aeste verursacht war $\left.^{2}\right)$.

Wenn nun die Sache sich so verhielte, wie ich sie eben als Frage aufgestellt habe, so wäre die bulbäre Affection ebenso als secundäre Affection im Anschluss an die cerebrale (Hämorrhagie) aufzufassen, wie die spinale (progressive Muskelatrophie) im Anschluss an die bulbäre; es wäre somit das von dem Kranken dargebotene Gesammtkrankheitsbild mit allen seinen Phasen (Hyperämie, Hämorrhagie, bulbäre und spinale Erkrankung) ein selten einheitliches Bild einer kettenförmigen Reihe von Ursachen und Wirkungen. Gegen diese Supposition ist aber zunächst einzuwenden, dass die Oblongataerkrankung auf der rechten, die cerebrale auf der linken Seite sich befindet; und da jene noch vor der Pyramidenkreuzung liegt, so müsste eigentlich die rechte Pyramide secundär degenerirt sein, wenn die rechtsseitige Bulbäraffection die Folge der secundären Degeneration der Pyramidenbahn wäre. Ferner ist in Betracht zu ziehen, dass selbst bei viel intensiveren Graden von secundärer Degeneration der Pyramidenbahnen (mit hochgradigen Contracturen und gesteigerten Sehnenreflexen) Erkrankungen der Oblongata als. Folgezustände bis jetzt noch nicht beobachtet wurden.

1) Leçons, Progrès medical 1877.

2) Arch. f. Psychiatrie. Bd. IX. S. 24.

Archiv f. pathol. Anat. Bd, CVI. Hft. I. 
Es muss demnach an der Annahme festgehalten werden, dass die ursprüngliche Eäsion der Oblongata eine langsam zunehmende capilläre Apoplexie gewesen sein dürfte, die allmählich zur rothen Erweichung, Sclerose und Narbenbildung der betreffenden Region führte, von welcher aus die Sclerose sich in die Tiefe, in die betreffende (rechte) Pyramide fortsetzte und von da aus auf dem Kreuzungswege sich in den linken Pyramidenstrang der Medulla spinalis, bezw. in die linke Vordersäule der Halsanschwellung verbreitete. Daraus würde sich die $1 \frac{1}{2}$ Jahre später aufgetretene Poliomyelitis anterior chronica linkerseits erklären. Die wieder etwa_ $1 \frac{1}{2}$ Jahre später aufgetretene und bis jetat nur sehr langsame Fortschritte machende rechtsseitige progressive Muskelatrophie (der rechten Hand) ist entweder durch das Hinüberkriechen des sclerotischen Prozesses von der linken auf die rechte Vordersäule oder durch das Hinabsteigen des Prozesses von der rechten Pyramide am Knotenpunkte der Pyramidenkreuzung auf den rechten Vorderseitenstrang (der überdies schon in Folge der cerebralen Hämorrhagie der secundären Degeneration unterworfen war) zu erklären, auf die Weise etwa wie Pitres bei einseitigen cerebralen Iäsionen das Hinabsteigen der secundären Degeneration in beide Seitenstränge des Rückenmarkes constatiren konnte.

\section{II.}

Im Folgenden will ich, wie ich dies in der Einleitung andeutete, einige seltenere Erscheinungen aus der Krankengeschichte des Sch. K. hervorheben und näher besprechen. Diese sind die Schmerzen auf der hemiplegischen Seite, der Singultus und die Mitbetheiligung der oberen $Z$ weige des Facialis an der Hemiplegie. Wie ersichtlich, sind dies lauter Erscheinungen, die mit der cerebralen Blutung im Zusammenhange stehen, und es sollen die letztgenannten 2 Erscheinungen noch durch je einen casuistischen Fall illustrirt werden. Vor Allem soll aber die Krankengeschichte hier ihren Platz finden, deren ich schon weiter oben als Pendant zu dem Falle von Sch. K. erwähnte, wo nehmlich eine massenhafte Hirnblutung ohne eigentlichen apoplektischen Insult zu Stande kam. 
2. Krankengesehichte.

Hochgradige Hirnblutung ohne apoplektisehen Insult.

L. E., 36 Jahre alt, verheirathet, aus Frankreich gebürtig, bis vor Kurzem Director einer Sesselfabrik in Finme, gegenwärtig bier wolnhaft, stellte sich mir in April 1884 mit folgendem Status vor: Es besteht seit 7 Monaten eine linksseitige complete Lühmung; der Kranke kann nicht ohne Stock gehen, schleppt die linke untere Extremität nach, und schleift sie beim Gehen auf der Erde. Die linke obere Extremität kann kaum etwas vom Stamme entfernt werden. Ellbogen gebengt, die Finger mässig eingezogen, Beugecontractur ziemlich stark ausgesprochen. Der linke Facialis in seinen unteren Aesten paretisch. Die Sensibilität auf der ganzen linken Hälfte herabgesetzt. Die Sprache langsam, undeutlich, oft kaum verständlich. In Bezug der Anamnese sagen der gebildete und intelligente Kranke und dessen Frau aus, dass er vor 7 Monaten auf der Reise von Budapest nach Fiume (seinen damaligen Wohnort) eine ganze Nacht auf der Eisenbahn zubrachte und daselbst gut schlief. Früh Morgens erwachte er noch mit vollständigem Wohlbefinden. Eine Stunde später bekam er heftige Kopfschmerzen, Schwindel und Brechneigung, welche Symptome etwa $\frac{1}{2}$ Stunde dauerten, worauf er plötzlich empfand, dass er das linke Bein nicht mehr heben könne. Später fühlte er auch im linken Arme eine Schwäche und Läbmung, und endlich konnte er anch die Zunge nicht mehr bewegen, bezw. kein Wort mehr sprechen.

Alles das ging in einem Zeitraume von $\frac{1}{2}$ Stunde vor sich, während welcher Zeit Patient stets bei vollem Bewusstsein blieb und dasselbe auch späterhin nicht verlor. Er bekam auch Schlingbeschwerden und Erbrechen, welch letzteres Symptom volle 8 Tage dauerte, und das ist eben jenes Symptom, was hier besonders hervorgehoben werden soll, da ein 8 Tage langes Erbrechen bei cerebralen Blutungen und bei Abwesenheit von gastrischen Erscheinungen eines der selteneren Phänomene ist. Weder Herzfehler noch Atherom der Arterien konnte nachgewiesen werden.

Einen Monat nach Beginn der Lähmung fing Pat. an zu sprechen, aber auch später blieb die Sprache, wie schon oben angedeutet wurde, sehr undeutlich. Bei dieser Gelegenheit sei hier gleich erwähnt, dass auf ausdrückliches Befragen der Patient angab gelinkt zu sein; daraus erklärt sich denn die hochgradige Aphasie, obwohl der hämorrbagische Heerd rechts gelegen ist. Zwei Monate nach der Hämorrhagie konnte Patient erst aus dem Bette steigen, da er erst jetzt auf den linken Fuss auftreten konnte; nach $3 \frac{1}{2}$ Monaten endlich fing er an auch den Arm etwas zu bewegen, zu welcher Zeit sich auch die Sensibilität der Haut einzustellen begann, da er bis dabin weder Nadelstiche noch Temperaturunterschiede fühlte.

Aus alledem muss man ohne $Z_{\text {weifel }}$ auf eine massenhafte Blutung schliessen, und zwar mit grösster Wahrscheinlichkeit auf eine solche im hinteren Drittel der hinteren Hälfte der 
inneren Kapsel, und dennoch hat, wie wir sehen, der apoplektische Insult gefehlt, im Gegensatz zu dem Falle von Sch. K., bei dem man mit Recht auf ein geringes Extravasat an eben derselben Stelle im Gehirne schliessen kann, und dennoch war das Zustandekommen desselben mit vollständigem Verluste der Besinnung in Verbindung. Es folgt aber hieraus, dass das Zustandekommen jenes Shock's, welcher die Erscheinung des apoplektischen Anfalles bewirkt, nicht so sehr von der Quantität des extravasirten Blutes, sondern von vielen anderen Verhältnissen, wie z. B. von der Grösse des durchbrochenen Gefässes, von der Grösse des Gefässrisses u. s. w. abhängt, wie dies Nothnagel in dem Capitel über Hirnblutungen (v. Ziemssen's Sammelwerk) in erschöpfender Weise auseinandersetzte. Hervorzuheben wäre hier noch das verhältnissmässig wenig vorgerückte Alter des Kranken, da er erst 36 Jahre alt war, als ihn die Hirnblutung traf.

Eine andere Frage ist die, wie soll man das 8 Tage lange Erbrechen erklären? Gewöhnlich wird häufiges Erbrechen mit Kleinhirnaffectionen in Verbindung gebracht, wobei dasselbe dem Drucke auf die Oblongata zugeschrieben wird. In unserem Falle ist jedoch der Blutheerd weit entfernt von dieser Gegend. Die Erfahrung lehrt, dass Erbrechen bei Hirnblutungen vorkommen kann, wo immer der Sitz derselben sei, nur ist das Erbrechen ausser bei Blutungen im Kleinhirn kein anhaltendes, sondern kommt höchstens am Tage der Apoplexie einige wenige Mal vor. Andererseits können Blutungen auch im Kleinhirn ganz ohne Erbrechen vorkommen. Das Erbrechen ist eine sog. diffuse Erscheinung, hervorgerufen durch intracraniellen Druck, ohne Rücksicht darauf, wodurch der Druck zu Stande kommt und wo immer der Druck erzeugende Heerd im Gehirn sich befinde, wenn nur der Druck gross genug ist, um seine Wirkung auch auf die Medulla oblongata fortzupflanzen. Indess braucht der Druck nicht immer die Medulla oblongata zu treffen. Auch Druck auf die Dura mater ist genügend, um Erbrechen $\mathrm{zu}$ erzeugen. Da kommt aber dasselbe auf reflectorischem Wege zu Stande, wie die Migräne beweist, wo das Erbrechen auf reflectorischem Wege au Stande kommt ohne Concurrenz von intracraniellem Drucke. Uebrigens kommen wir noch ohnehin 
weiter unten wieder auf dieses Phänomen zurück; es sei hier nur bemerkt, dass, was immer auch die Ursache des Erbrechens bei Hirnhämorrhagien sei, ein $8 \mathrm{~T}$ age anhaltendes Erbrechen ohne gastrische Erscheinungen bei Blutungen im Grosshirn ein seltenes Ereigniss ist. -

Nun sollen im Folgenden die schon oben erwähnten drei, den Patienten Sch. K. betreffenden Krankheitserscheinungen näher besprochen werden:

A) Wie wir in der Krankengeschichte gesehen haben, hatte Pat. vom Beginne der capillaren Hirnblutung Schmerzen, und zwar anfangs blos in der rechten Hand, die sich dann mit dem Eintritt der vasculären Blutung auf den ganzen Arm, die rechte Thorax-, Hals- und Kopfseite ausbreiteten. Dieses Symptom ist von allen Erscheinungen so zu sagen das persistenteste und hartnäckigste, da dasselbe den Kranken auch jetzt noch continuirlich, bald in schwächerem bald in stärkerem Grade belästigt, und die Schmerzen bald blos auf den Arm beschränkt, bald auch weiter verbreitet sind.

In den über Hirnhämorrhagien handelnden Lehrbüchern ist nur von solchen Schmerzen die Rede, welche ein par Tage oder Wochen nach dem apoplektischen Anfall erscheinen, und diese werden dann, wenn sie früh erscheinen, der um den Heerd sich etablirenden reactiven Entzündung, wenn sie spät erscheinen, der durch die Narbenbildung vor sich gehenden Schrumpfung und Zerrung der in sie einlaufenden Nervenfasern zugeschrieben. In unserem Falle waren aber die Schmerzen (und das Ameisenkriechen) das erste und einzige Heerdsymptom der capillaren Apoplexie im Gehirne. Die darauf folgende vasculäre Blutung hatte nur die sofortige Verstärkung und grössere Ausbreitung der Schmerzen zur Folge. Diese Schmerzen kann man demnach weder der reactiven Entzündung noch der Narbenbildung zuschreiben, sondern sie müssen als primäres und directes Heerdsymptom aufgefasst werden, und das ist es eben, auf was ich hier aufmerksam machen will, und was in der Semiotik der Heerdsymptome von Hirnblutungen bis jetzt noch nicht gewürdigt wurde.

Die neuropathologischen Erfahrungen haben es als unzweifel- 
haft erwiesen, dass es besondere Nervenfasern für die Schmerzempfindung und besondere für die Tastempfindung giebt. Die Reizung dieser letzteren bringt das Gefühl von Ameisenkriechen und Kriebeln, die der ersteren Schmerzen hervor. Es ist jedenfalls eine auffallende Sache, dass, während das Pelzigsein und Ameisenkriechen schon im Beginn der Hirnblutungen eine häufige Erscheinung ist, und zwar oft in Begleitung von Anästhesie, der Schmerz im Beginne der Hirnapoplexie eine höchst seltene Erscheinung ist.

Es fragt sich nun, welcher Art kann möglicherweise die Verletzung jener Fasern im Gehirn sein, die mit Schmerzen verbunden ist? Wenn irgend eine die Schmerzempfindung zum Gehirn leitende Nervenfaser wo immer in ihrem Verlaufe in ihrer Continuität unterbrochen wird, so wird im Moment des Zerreissens Schmerz empfunden, der auf den entsprechenden Punkt der peripherischen Verbreitung localisirt wird. Dann ist aber dieser Punkt anästhetisch oder vielmehr analgetisch geworden. Wenn aber die Schmerzemptindung in irgend einem Nervengebiet ununterbrochen fortbesteht, so muss angenommen werden, dass die betreffenden Nervenfasern nicht gerissen sind, oder wenn sie anfangs zerrissen waren, dass sie wieder entweder unmittelbar oder mittelst Narbengewebes zusammengewachsen sind. Dieser letztere Vorgang tritt bei allen jenen Fällen ein, wo die Schmerzen melurere Wochen nach der Hirnhämorrhagie beginnen.

Wenn in Folge capillärer oder stärkerer Blutung, wie in unserem Falle, sich gleich im Anfang Schmerzen einstellen und nachher continuirlich fortbestehen, so ist dies nur so zu verstehen, dass die betreffenden Fasern im Gehirn nicht zerrissen, sondern blos einem Druck oder einer Zerrung von Seiten des Extravasates ausgesetzt sind; und wenn die Schmerzen auch nach Resorption des Extravasates, die in unserem Falle nach Verlaufe von so vielen Jahren ohne Zweifel geschehen sein musste, fortdauern, so kann man annehmen, dass entweder das nachträglich gebildete Narbengewebe die Rolle des Extravasates übernommen hat, indem die betreffenden Fasern einer fortwäbrenden Zerrung durch das Narbengewebe ausgesetzt sind, oder, dass während der Zeit des Druckes oder der Zerrung von Seite des Extravasates in den Nervenfasern selbst derartige Veränderungen 
(Verdickungen der Schwann'schen Scheide oder des Axencylinders oder irgend eine andere Veränderung) vorgekommen sind, durch welche ein fortwährender Reizungszustand in denselben unterhalten wird.

B) In der Anamnese haben wir gesehen, dass der Kranke noch am Tage der Apoplexie Abends Singultus bekam, welcher 6 Tage anhielt. Ich hebe dieses Phänomen hier besonders darum hervor, weil von demselben in den Lehrbüchern über Hirnapoplexien nirgends die Rede ist. Ich habe dieses Symptom mit Ausnahme von Läsionen des verlängerten Markes überhaupt bei keiner Kraukheit sei es des Gehirns, sei es der Hirnhäute aufgezählt gefunden; weder bei der Meningitis, noch bei Hirnembolien oder Erweichungen, weder bei Hirnsyphilis, noch bei Geschwïlsten, mit einem Worte nirgends. Selbst in der Semiotik der einzelnen Hirnsymptome in den bekannten Lehrbüchern von Nothnagel (Topische Diagnostik der Gehirnkrankheiten) und Wernicke (Lehrbuch der Gehirnkrankheiten) ist das Schluchzen nicht mit einem Worte erwähnt. Ueberall wird nur von Erbrechen, dann von Anomalien der Respiration, des Pulses, der Temperatur u. s. w. gehandelt, aber nicht von Schluchzen, und doch ist die Pathogenesis des Schluchzens dieselbe, wie die der eben erwähnten übrigen Erscheinungen; es wird eben so gut wie jene vom verlängerten Mark ausgelöst, nur dass z. B. das Erbrechen vom Brechcentrum, das Schluchzen vom Respirations- oder vom Singultus-Centrum ausgelöst wird. Schon aus alledem ist zu ersehen, dass das Schluchzen bei Hirnkrankheiten im Allgemeinen (mit Ausnahme von Erkrankungen der Medulla oblongata) und in specie bei Hirnblutungen zu den grössten Seltenheiten 'gehört. M. Rosenthal (Wien) weiss sich, wie ich aus mündlicher Mittheilung von ihm erfahren habe, blos auf einen Fall zu erinnern, wo er bei Apoplexie Singultus beobachtet hat.

Ich hebe demnach dieses Phänomen bei unserem Pat. um so mehr hervor, da ich in der Lage war, im Verlaufe des letztverflossenen Winters noch einen 2. Fall von schwerer Hirnapoplexie zu beobachten, in deren Verlaufe ebenfalls Sin. 
gultus vorkam, natürlich ohne Intercurrenz eines Magen- oder anderen Uebels, welches an und für sich oft mit Singultus verbunden ist, wie denn eine solche Complication auch bei Sch. K. ausgeschlossen werden muss.

\section{Krankengeschichte.}

$Z$ weiter Fall von Singultus bei Hirnapoplexie.

Am 18. October 1884 wurde ich zu einem 60jäbrigen Kaufmann (F.A.) gerufen, der von einer ganz frischen, so zu sagen vor meinen Augen noch sich ausbildenden Hirrbämorrhagie befallen war, mit der sich gleichzeitig eine linkseitige totale Hemiplegie einstellte. Der Kranke war 2 Tage lang in fortwährender Somnolenz, hat auch im Beginn 2-3mal erbrochen, konnte schwer schlucken und sprechen. Am 3. Tag kam er wieder zu sich und befand sich mit Ansnahme der Hemiplegie ziemlich wohl, bis er am 5. Tage der Apoplexie Scbluchzen bekam, welches 4 Tage, Tag und Nacht, anbielt. Die Zwerchfellskrämpfe kamen alle 10-15 Minuten in Form rasch auf einander folgender klonischer Zuckungen, die die Bauchwand ziemlich stark erschütterten. Es war weder ein Brustleiden noch ein Magen - oder Bauchleiden vorhanden. Pat. war während der Zeit, wo das Schluchzen andauerte, stets bei Bewusstsein, und selbst die mittelbaren Heerdsymptome, wie die Scbling- und Sprachbeschwerden, hatten sich während dieser Zeit erheblich gebessert. Mehrere innerlich angewendete Mittel (Morphium u. s. w.) halfen nichts, während wiederholtes Elektrisiren mit dem faradischen Strom den Singultus beseitigte.

Nebenbei will ich noch diese Krankengeschichte mit folgenden Daten ergänzen, obwohl dieselben streng genommen nicht mehr bieher gehören, aber sie sind wegen der Schwere des Verlaufes und des endlichen Ueberganges in Genesung von Interesse. Der Kranke befand sich nachber noch 3 Tage, die fortbestehende Hemiplegie abgerechnet, ziemlich wobl. Dann wurde er aber wieder soporös, und es stellten sich die schwersten Erscheinungen einer um den Heerd sich etablirenden reactiven Encephalitis ein, wie Fieber, Delirium, ungeheure Schmerzen und klonische Zuckungen in den hemiplegischen Extremitäten, Schlaflosigkeit, unwillkürliches Uriulassen und Stuhlabsetzen, und es entwickelten sich zahlreiche Decubitusstellen auf der hemiplegischen Seite. Bemerkenswerth war das fortwährende Greifen der gesunden Hand nach den Genitalien, sowie der Umstand, dass die Schmerzen und klonischen Zuckungen besonders des Nachts heftig waren. Als ich den Kranken in dieser Behandlungszeit am 31. December 1884 zum letztenmal sah, hatte dieser schwere Zustand bereits 10 Wochen ununterbrochen ohne die mindeste Besserung angedauert, mit Ausnabme der Decubitusstellen, die der Reihe nach heilten. Um so mehr war ich überrascht, als ich, 6 Wochen später, zu demselben Kranken gerufen wurde und ihn wohl noch wegen allgemeiner Schwäche im Bette liegend, aber sonst ganz bergestellt fand. Es war nicht nur jede Spur der Encephalitis, sondern anch der Hemiplegie geschwunden. Hier 


\section{1}

war demnach der Sitz der Hämorrhægie wahrscheinlich im Nucleus caudatus und lenticularis, und hatte die Capsula interna blos in ihrer vorderen Hälfte getroffen.

Hier also haben wir wieder Schluchzen im Verlaufe einer Hirnhämorrhagie! Ich halte es nicht wahrscheinlich, dass der Singultus in diesen beiden Fällen eine blos zufällige Complication der Hirnhämorrhagie war. Denn da wir schon im vornherein jede Ursache des Schluchzens ausgeschlossen haben, die auf eine organische Veränderung in anderen Organen, von denen aus, wenn sich dieselben in einem Reizungszustand befinden (Pleura, Peritonäum, Magen u. s. w.), Schluchzen als Reflexerscheinung ausgelöst wird, nachdem wir ferner auch andere allgemeine Neurosen (Hysterie) ausschliessen können, in deren Begleitung Schluchzen vorzukommen pflegt, so halte ich dafür, dass dasselbegeradeso, wie etwa das Erbrechen, mit der Hirnhämorrhagie in ursächlichem Zusammenhange stehe. Nun ist aber die Frage, wie dieser ursächliche Zusammenhang in diesen Fällen zu erklären ist?

In beiden Fällen ist das Schluchzen unter Verhältnissen aufgetreten, welche nicht etwa einen bedeutenden intracraniellen Druck, wenigstens keinen solchen vermuthen lassen würden, der auch auf das verlängerte Mark sich hätte ausdehnen können. Bei Sch. K. ist diese Annahme schon durch die Kleinheit des Heerdes ausgeschlossen. Bei F. A. kann ebenfalls nicht an einen bedeutenden intracraniellen Druck gedacht werden, da das Schluchzen zu einer Zeit aufgetreten ist, wo sich der Kranke schon 2 Tage hindurch wohl fühlte und an einen solchen Druck nicht mehr gedacht werden konnte. Der neuerdings durch die Encephalitis bedingte intracranielle Druck ist aber erst 3 Tage nach Aufhören des Schluchzens eingetreten. Somit bleibt nichts Anderes übrig, als den Vorgang als auf reflectorischem Wege zu Stande gekommen zu erklären. Auf welche Weise jedoch dieser Reflex ausgelöst wurde, ist sehr schwer zu sagen.

Wir wissen, dass das Schluchzen bei Hysterie eine sehr häufige Erscheinung ist; ob aber dasselbe auf reflectorischem Wege zu Stande komme, oder durch die sog. "functio- 
nelle" Erkrankung der Medulla oblongata selbst, können wir um so weniger bestimmen, da wir den eigentlichen Sitz der Hysterie noch gar nicht kennen, obwohl allerdings die Erscheinungen im jetzigen Lichte der Wissenschaft gesehen dahin drängen, ihren Sitz in das Gehirn zu verlegen. Was die übrigen ursächlichen Momente des Schluchzens anlangt, so wissen wir, dass dasselbe zunächst bei Reizzuständen des N. phrenicus selbst (Compression durch hypertrophirte Drüsen u. s. w.), dann aber auch, und das ist wohl die häufigste Ursache des Schluchzens, auf reflectorischem Wege von Seite der Verdaungs-, Respirations- und Urogenitalorgane, sowie im Allgemeinen durch Reizungszustände der serösen Häute zu Stande kommt. Da von der Dura mater, wie wir schon oben sahen, Erbrechen auf reflectorischem Wege ausgelöst werden kann, selbst wenn sie nicht gerade einem starken Drucke ausgesetzt ist (Migräne), so wäre es immerhin möglich, dass auch im Verlaufe einer Hirnhämorrhagie von der Dura mater aus auf reflectorischem Wege unter gewissen Umständen Schluchzen ausgelöst werden kann, selbst wenn der intracranielle Druck ein sehr geringer ist ${ }^{1}$ ).

C) Bei der Aufnahme des Kranken Sch. K. konnte ich deutlich constatiren, dass neben einer Parese der unteren Zweige des Facialis rechterseits auch eine solche der oberen Zweige dieses Nerven bestand. Allerdings konnte blos eine Parese des rechten $\mathrm{M}$. frontalis und corrugator superciliae, jedoch keine solche des Orbicularis orbitae constatirt werden, worïber weiter unten die Rede sein wird.

Bei peripherischen Facialislähmungen sind bekanntlich

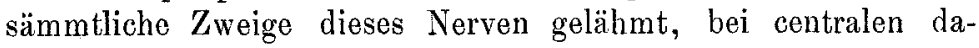
gegen in der Regel nur die unteren - respiratorischen $Z$ weige. Nur bei Ponsaffectionen, wenn die Läsion in der unteren Hälfte des Pons sitzt, sind zugleich auch die Frontoorbitalzweige gelähmt. Dieser Umstand wird dadurch erklärt, dass beiderlei

1) In den Lebrbüchern der Pathologie heisst es allgemein, dass das Erbrechen bei Migräne oder intracraniellem Drucke durch Reflex von Seite der Trigeminuszweige der Dura mater ausgelöst wird. Mir ist es indessen wahrscheinlicher, dass in diesen Fällen das Erbrechen durch den Ramus meningeus n. vagi vermittelt wird. 
Zweige vom psychomotorischen Centrum an bis zur unteren Hälfte des Pons getrennt auf verschiedenen Bahnen verlaufen, dass namentlich die unteren $Z$ weige durch die ganze Länge der Capsula interna verlaufen, um in die Pedunculi cerebri einzutreten, während die oberen $Z$ weige auf dem $W$ ege der sog. Linsenkernschlinge dahin gelangen (Meynert). Huguenin und Chwostek haben durch Autopsien constatirt, dass in Fällen von Affection der Linsenkernschlinge auch die oberen $Z$ weige des Facialis mitafficirt waren.

Kétli hatte im Jahre 1884 im hiesigen ärztlichen Vereine 2 Fälle von Hirnläsion vorgezeigt, bei denen nebst den unteren Zweigen des Facialis auch die oberen gelähmt waren. Die Krankheitsheerde konnten bei beiden in die vordere Centralwindung verlegt werden; da aber beiderlei $Z$ weige des $\mathrm{Fa}$ cialis schon hier ihre getrennten Centra haben, so musste angenommen werden, dass diese beiden Centra afficirt gewesen sein dürften. In unserem Falle jedoch ist der Heerd im hintersten Theile der Capsula interna, und nachdem auch die oberen $\mathrm{Z}$ weige des Facialis paretisch sind, so muss als wahrscheinlich angenommen werden, dass auch die Linsenkernschlinge mitafficirt sei.

Oben hatten wir gesagt, dass Parese des rechten Orbicularis orbitae bei unserem Kranken nicht constatirt werden konnte, und dennoch muss es als wahrscheinlich gelten, dass auch dieser Muskel paretisch gewesen sei, und zwar aus folgender Ursache: Bei einseitigen peripherischen Facialislähmungen, wo also auch die oberen Ziweige afficirt sind, verhält sich die Sache bekanntlich so, dass wenn der Kranke beide Augen auf einmal schliessen will, sich blos das der gesunden Seite schliesst, während das der gelähmten offen bleibt. Im Grunde genommen sollte dies auch der Fall sein bei allen jenen centralen Lähmungen des Facialis, wo auch die oberen Zweige mitafficirt sind; dies ist aber nicht immer so. Es giebt nehmlich derartige Fälle, wo der Kranke, wenn er beide Augen auf einmal schliessen will, das wohl kann, was also eigentlich keine Lähmung vermuthen liesse. Will er aber die Augen. einzeln schliessen, so sehen wir, dass er das Auge der gesunden Seite wohl für sich allein schliessen kann, wobei das der gelähmten Seite 
offen bleibt; will er aber letzteres für sich allein schliessen, so gelingt das nicht, ohne dasser zu gleicher Zeit auch das der gesunden Seite schliesst. Daraus folgt, dass die Willensbewegung auf der gelähmten Seite aufgehört hat, und nur noch die synergische Bewegung besteht, was jedenfalls auf Lähmung hinweist.

Darauf, dass die oberen Zweige des Facialis bei cerebralen Lähmungen gelähmt sein können, ohne dass sie zu functioniren aufgehört hätten, dass sie also scheinbar nicht gelähmt sind, hat bekanntlich zuerst M. Potain und später M. Simoneau ${ }^{1}$ ) aufmerksam gemacht. Letzterer stützt seine Behauptung auf 11 mitgetheilte Fälle. Broadbent hat übrigens gezeigt, dass diese Regel auch auf die Muskeln des Pharynx, des Diaphragma, kurz auf alle Muskeln mit associirten Bewegungen Bezug hat. Indess ist dieses in Rede stehende Phänomen am Orbicularis orbitae nicht bei jedem Patienten zu demonstriren, da in Bezug auf gewisse Muskeln die Willensinnervation nicht bei jedem Menschen die gleiche ist. So können manche Menschen ihre Ohren überhaupt nicht, oder doch nur in gewissen Richtungen, z. B. nach oben oder nach vorne, nicht bewegen. Andere sind wieder überhaupt nicht im Stande, willkürlich ihre Stirne oder ihre Augenbrauen in Runzeln zu bringen. So steht nun die Sache bei dem Kranken Sch. K. in Bezug auf den Orbicularis orbitae. Während die meisten Menschen jedes Auge für sich allein zu schliessen im Stande sind, konnte unser Kranker wahrscheinlich in der vorhemiplegischen Zeit auch nicht jedes Auge für sich separat schliessen; denn er liann jetzt nicht nur das Auge der gelähmten Seite, sondern auch das der gesunden Seite nicht für sich allein schliessen; es werden immer unwillkürlich beide zugleich geschlossen, ob er das der gesunden oder das der kranken Seite für sich allein schliessen will. Es war demnach bei ihm die Paresis des rechten Orbicularis orbitae nicht nachzuweisen. Ich habe indess Gelegenheit gehabt, dieselbe auf die oben bezeichnete Weise an einer anderen, ebenfalls mit Haemorrhagia cerebri behafteten

1) Simoneau, De la conservation de mouvements associés dans les hémiplégies de cause cërébrale. Thèse, Paris 1877, Jahresber. d. ges. Med. v. Virchow u. Hirsch. 1877. 
Kranken zu beobachten, bei der ebenfalls die oberen $Z$ weige des Facialis auf der hemiplegischen Seite gelähmt waren.

4. Krankengeschichte.

2. Fall von Lähmung der oberen $Z$ weige des Facialis bei Hirnblutung.

Sch. Jul., 45 Jahre alt, verheirathet, Müllersfrau, bekam am 10. Juni 1884 einen schweren apoplektischen Anfall. Als ich die Kranke 4 Monate später (October 1884) zum erstenmal sah, bestand noch eine hochgradige rechtseitige totale Lähmung in ihrer classischen Form, indem nebst der motorischen und sensitiven auch sensorielle Lähmung (auch des Gehörsinns) zugegen war. Die rechte obere Extremität hing ohne jedwede Beweglichkeit herab; Gang sehr schwer, ohne Stock unmöglich, Contracturen an beiden Extremitäten, hochgradige Aphasie, die gesprochenen Worte klangen ganz anders als die Worte, die ausgesprochen werden sollten, indem kaum ein Selbst- oder Mitlaut von den beabsichtigten in den ausgesprochenen Worten aufzufinden war. Zwei Monate lang soll übrigens die Kranke ganz stumm gewesen sein; drei Monate lang war sie bettlägerig, während welcher Zeit sie an ausgebreiteten Decubitus rechterseits litt, der nur sebr langsam beilte.

Nebst den unteren Zweigen des Facialis waren auch die oberen gelähmt. Die rechte Stirn konnte kaum etwas in Runzeln gehoben werden, dagegen die linke sehr gut; dasselbe gilt vom Corrugator superciliae rechts im Vergleiche zu links. Beide Augen konnten zu gleicher Zeit ganz gut. geschlossen werden; das rechte Auge konnte für sich allein nicht geschlossen werden, dagegen das linke Auge für sich allein ganz gut. Aber wenn auch die Kranke beide Augen zugleich schloss, lronnte sie bei forcirtem Schliessen die Lider der gelähmten Seite nicht so stark in Runzeln falten, wie die der gesunden Seite. - Hier kann also kein Zweifel darüber obwalten, dass der Sitz des hämorrhagischen Heerdes im hinteren Drittel der hinteren Hälfte der Capsula interna war, und ebenso zweifellos ist es, dass auch die Orbitofrontaläste des rechten Facialis gelähmt waren, wobei aber die Lähmung des rechten Orbicularis orbitae ganz wohl demonstrirt werden konnte im Gegensatze zu dem Kranken Sch. K., wo dies auf directem Wege nicht möglich war. 